\title{
MECANISMOS DE ARREGLO DE DIFERENCIAS ENTRE INVERSORES Y ESTADOS (ISDS) Y LA AUTONOMÍA DEL ORDENAMIENTO JURÍDICO DE LA UNIÓN EUROPEA: ¿̇UNA ECUACIÓN (IM)POSIBLE?
}

\author{
IÑIGO IRURETAGOIENA AGIRREZABALAGA ${ }^{1}$ \\ Universidad del País Vasco (UPV/EHU) \\ inigo.iruretagoiena@ehu.es
}

Cómo citar/Citation

Iruretagoiena Agirrezabalaga, I. (2018).

Mecanismos de arreglo de diferencias entre inversores y estados (ISDS)

y la autonomía del ordenamiento jurídico de la Unión Europea: ¿̇una ecuación (im)posible?

Revista de Derecho Comunitario Europeo, 59, 219-262.

doi: https://doi.org/10.18042/cepc/rdce. 59.06

\section{Resumen}

Los mecanismos para el arreglo de diferencias entre Estados e inversores (ISDS) en la Unión Europea se encuentran en una difícil encrucijada. Tras la decisión en el asunto Achmea, que declara la incompatibilidad del arbitraje de inversiones previsto en un APPRI intra-UE con el derecho de la UE, las trompetas suenan la retirada para buena parte de los mecanismos ISDS presentes hoy en Europa. Por su parte, a raíz de la presentación de una solicitud por parte de Bélgica de una opinión sobre la compatibilidad del nuevo sistema de tribunales de inversión previsto en el CETA, gran parte de su futuro está hoy en manos del TJUE. Si se observa la actitud de desconfianza que el

1 Profesor agregado de Derecho Internacional Público en la Universidad del País Vasco (UPV/EHU). Trabajo realizado en el marco de las actividades de investigación del Grupo de Investigación Consolidado del Gobierno Vasco (referencia IT1039-16), del proyecto de investigación financiado por la UPV/EHU «Persona, empresa y derechos humanos en una sociedad globalizada» y del proyecto de investigación DER201565486-R financiado por el Ministerio de Economía y Competitividad. 
Tribunal Europeo viene mostrando respecto a otras jurisdicciones externas, se advierte que la jurisprudencia del TJUE, centrada en la interpretación de la noción de autonomía del ordenamiento jurídico de la Unión, se antoja premonitoria y poco halagüeña para el futuro de los mecanismos ISDS. En cualquier caso, y a pesar de la sentencia de Achmea, existen razones suficientes de carácter jurídico y de oportunidad política que invitan a una relectura del concepto de autonomía, de modo que sea posible establecer un escenario de confianza y colaboración donde el diálogo entre distintos tribunales sea una opción real.

\title{
Palabras clave
}

Arbitraje; autonomía; inversiones; mecanismos ISDS; órgano jurisdiccional de un Estado miembro; TJUE; Unión Europea.

\section{INVESTOR-STATE DISPUTE SETTLEMENT MECHANISMS (ISDS) AND THE AUTONOMY OF THE EUROPEAN UNION LEGAL ORDER: AN (IM) POSSIBLE EQUATION?}

\begin{abstract}
The ISDS mechanisms in the European Union are at a difficult crossroads. After the decision in the Achmea case, which declares the incompatibility of the investment arbitration provided in an intra-EU BIT with the EU law, the trumpets sound a retreat for much of the present of the ISDS mechanisms in Europe. Moreover, much of the future of the ISDS mechanisms, after the request of an opinion by Belgium on the compatibility of the new Investment Court System included in CETA, is today in the hands of the CJEU. If one observes the attitude of distrust that the European Court has shown until now regarding other external jurisdictions, it is noted that the jurisprudence of the CJEU, focused on the interpretation of the notion of autonomy of the legal system of the Union, seems premonitory and not very favorable to the compatibility of ISDS mechanisms. Yet, and despite Achmea's judgment, there are enough reasons of a legal nature and political opportunity that call for a new reading of the concept of autonomy, making it possible to establish a scenario of trust and collaboration where dialogue between different courts is a real option.
\end{abstract}

\section{Keywords}

Arbitration; autonomy; investments; ISDS mechanisms; court or tribunal of a Member State; international court; CJEU, European Union. 


\section{MÉCANISMES DE RÈGLEMENT DES DIFFÉRENCES ENTRE LES INVESTISSEURS ET LES ÉTATS (ISDS) ET L'AUTONOMIE DE L'ORDRE JURIDIQUE DE L'UNION EUROPÉENNE: UNE ÉQUATION (IM)POSSIBLE?}

\section{Résumé}

Les mécanismes de l'ISDS dans l'Union Européenne sont à un carrefour difficile et semblent être aujourd'hui entre les mains de la CJUE. Après la décision dans l'affaire Achmea, qui déclare l'incompatibilité de l'arbitrage d'investissement prévu dans un TBI intra-UE avec le droit de l'UE, les trompettes sonnent la retraite pour une bonne partie des mécanismes actuels de l'ISDS en Europe. Pour sa part, la Court doit aussi trancher sur une grande partie de l'avenir de ces mécanismes, suite à la demande d'un avis de la Belgique sur la compatibilité du nouveau système des tribunaux des investissements prévu dans le CETA. Si l'on s'en tient à l'attitude de méfiance que la Cour Européenne a manifestée à l'égard des autres juridictions externes, faudrait signaler que la jurisprudence de la CJUE, centrée sur l'interprétation de la notion d'autonomie de l'ordre juridique de l'Union, semble prémonitoire et peu clémente sur la compatibilité des mécanismes ISDS. Cependant, et malgré l'arrêt d'Achmea, il y a des raisons suffisantes de nature juridique et d'opportunité politique qui invitent à relire le concept d'autonomie, de sorte qu'il soit possible d'établir un scénario de confiance et de collaboration où le dialogue entre les différentes juridictions soit une option réelle.

\section{Mots clés}

Arbitrage; autonomie; investissements; mécanismes ISDS; juridiction d'un des États membres; tribunal international; CJUE; Union Européenne. 


\section{SUMARIO}

I. CONSIDERACIONES INTRODUCTORIAS: EL INCIERTO FUTURO DE UNA INSTITUCIÓN CUESTIONADA. II. LOS MECANISMOS ISDS EN LA UNIÓN EUROPEA: UNA REALIDAD HETEROGÉNEA Y CAMBIANTE. III. LA COMPATIBILIDAD DE LOS MECANISMOS ISDS DESDE LA PERSPECTIVA DE LA AUTONOMÍA DEL ORDENAMIENTO JURÍDICO DE LA UNIÓN EUROPEA: 1. Aspectos generales de la problemática: cartografía de un terreno pantanoso. 2. Tribunales de inversión como «órganos jurisdiccionales de un Estado miembro». 3. Tribunales de inversión como tribunales externos al sistema jurisdiccional de la Unión Europea: 3.1. Los mecanismos ISDS y el artículo 344 TFUE. 3.2. Tribunales de inversión y la salvaguardia de las características específicas de la Unión y de su derecho. IV. CONCLUSIONES. BibLIOGRAFíA.

\section{CONSIDERACIONES INTRODUCTORIAS: EL INCIERTO FUTURO DE UNA INSTITUCIÓN CUESTIONADA}

Los mecanismos para el arreglo de diferencias entre Estados e inversores (mecanismos ISDS), tradicionalmente identificados con el arbitraje inversor-Estado o arbitraje de inversiones, se encuentran hoy en la Unión Europea (UE) en una difícil encrucijada. En el marco de las negociaciones abiertas por la Unión para la celebración de Tratados de Libre Comercio e Inversiones (TLCI) con terceros Estados, la oportunidad de incorporar estos mecanismos a su articulado está siendo seriamente cuestionada. No resulta exagerado afirmar que los mecanismos ISDS constituyen uno de los elementos más contestados y polémicos, si no es el más, de la renovada y ampliada política comercial común de la Unión y, por tanto, de los TLCI de nueva generación que la Unión trata de impulsar. El debate en torno a estos mecanismos abar$\mathrm{ca}$, al menos, tres dimensiones diferenciadas: en primer lugar, la relativa a la competencia para adoptar compromisos en materia de arreglo de diferencias entre Estados e inversores; en segundo lugar, la de la legitimidad de los ISDS como alternativa a los tribunales internos de los Estados y; en tercer lugar, la referida a la compatibilidad de los mecanismos ISDS con el ordenamiento jurídico de la Unión. 
En relación con la primera de las dimensiones del debate, se ha cuestionado si la competencia de la Unión en materia de inversiones extranjeras directas tras la entrada en vigor del Tratado de Lisboa (Hinojosa Martínez, 2015: 871-907) permite a la Unión introducir mecanismos ISDS en sus acuerdos de inversión futuros. El Tribunal de Justicia de la Unión Europea (TJUE), en su Dictamen 2/15, en referencia al mecanismo ISDS del TLCI entre la UE y Singapur, se ha manifestado de forma inequívoca, mas empleando argumentos escasamente elaborados (Díez-Hochleitner, 2017: 424), al señalar que tratándose de un régimen que «sustrae diferencias a la competencia jurisdiccional de los Estados miembros, no puede tener carácter meramente

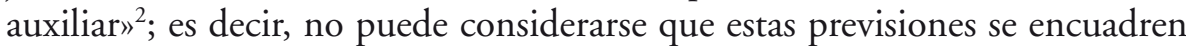
en la misma competencia que corresponda a las disposiciones sustantivas a las que acompañan ${ }^{3}$. Ello ha conducido al TJUE a concluir que se trata de una competencia compartida entre la Unión y los Estados miembros (Iruretagoiena Agirrezabalaga, 2017a: 1-19).

La dimensión más mediática y de mayor carga ideológica de las críticas vertidas sobre el arbitraje de inversiones hace referencia, seguramente, a aquella que cuestiona su legitimidad como alternativa válida a los tribunales internos de los Estados. En este sentido, es por todos conocida la radical oposición que mantienen algunos colectivos de la sociedad civil europea frente a los mecanismos ISDS, detonada tras el inicio de las negociaciones, hoy encalladas, del acuerdo de Asociación Transatlántica de Comercio e Inversión (TTIP) entre la UE y EE. UU., y posteriormente extendida al Acuerdo Económico y Comercial Global (CETA) entre la UE y Canadáa . La perseverancia de las campañas anti-TTIP y anti-CETA ha logrado situar el debate sobre la legitimidad de los mecanismos ISDS bajo el foco de la opinión pública europea, propiciando una corriente de opinión abiertamente hostil respecto a los mismos.

2 Dictamen 2/15 del Tribunal de Justicia de 16 de mayo de 2017, EU:C:2017:376, apdo. 292.

3 Ibid., apdo. 276.

4 DO L 11, de 14 de enero de 2017, p. 23. Desde el 21 de septiembre de 2017, el CETA se aplica provisionalmente. Sin embargo, no se aplican provisionalmente la sección relativa a la protección de las inversiones, salvo el artículo sobre transferencias, y la sección relativa a la resolución de diferencias entre inversores y estados. Asimismo, los apartados del capítulo octavo que sí son de aplicación solo lo serán en la medida en que se refieran a una inversión extranjera directa. Véase Decisión (UE) 2017/38 del Consejo, de 28 de octubre de 2016, relativa a la aplicación provisional del Acuerdo Económico y Comercial Global (AECG) entre Canadá, por una parte, y la Unión Europea y sus Estados miembros, por otra, (DO L 11, de 14 de enero de 2017, p. 1080). 
Sin embargo, no sería justo, ni ajustado a la realidad, trasladar la impresión de que el debate sobre la legitimidad del arbitraje de inversiones es resultado de esta reciente movilización social. Bien al contrario, en primer lugar, es necesario recordar que prácticamente desde sus propios orígenes han existido posicionamientos contrarios al arbitraje de inversiones ${ }^{5}$. En segundo lugar, a raíz de la masiva, y a veces compulsiva, celebración a escala global de acuerdos para la promoción y protección recíproca de inversiones (APPRI, BIT en su acrónimo en inglés) se ha experimentado una creciente multiplicación de las disputas de inversión (UNCTAD, 2017), lo que ha servido para poner de manifiesto la trascendencia pública de estas controversias, así como para identificar las debilidades y carencias de sistema (Blackaby, 2004; Franck, 2005: 1521-1625; Howse, 2017). Este hecho ha favorecido tanto planteamientos doctrinales como posicionamientos estatales que, desde una visión crítica del arbitraje inversor-Estado inspirado en un modelo «comercial», reclaman la revisión del mecanismo en aras a adaptarlo a la tipología de controversias que hoy se someten a su juicio ${ }^{6}$. En tercer lugar, incluso en el contexto de la nueva política de inversiones de la Unión, las propias instituciones de la UE partían de una lectura crítica del derecho de las inversiones extranjeras, en general, y del arbitraje de inversiones, en particular ${ }^{7}$. Por tanto, desde el primer momento,

5 Ese fue el caso, por ejemplo, de los países latinoamericanos que, en el contexto de las negociaciones del Convenio de Washington de 1965 mediante el que se crea el CIADI, adoptaron una posición colectiva de rechazo del CIADI y, por tanto, del arbitraje de inversiones, durante la Reunión Anual de los Gobernadores del Banco Mundial celebrada en Tokio, en 1964, conocida como el «no de Tokio». Véanse Broches (1995: 267); Parra (2014: 330).

6 Sirvan como botón de muestra: la denuncia del Convenio de Washington de 1965 (Convenio CIADI) por parte de Bolivia (efectiva desde el 3 de noviembre de 2007), Ecuador (efectiva desde el 7 de enero de 2010) y Venezuela (efectiva desde el 25 de julio de 2012); la propuesta de creación de un nuevo Centro de Solución de Controversias en Materia de Inversiones de Unasur (véanse Echaide, 2017: 369-403; Fach Gómez y Titi, 2016: 3-6); la posición del Gobinerno laborista en 2011 a favor la supresión de los mecanismos ISDS de los Acuerdos celebrados por Australia, flexibilizada tras el cambio de Gobierno en 2013 (véase Gillard Government Trade Policy Statement: Trading our way to more jobs and prosperity, 2011, p. 14., diponible en https://goo.gl/BeQUYZ (todas las direcciones electrónicas recogidas en este trabajo han sido consultadas por última vez el 31 enero de 2018); o la revisión del modelo de APPRI impulsado por la India (Investment Treaty News, vol. 7, núm. 3, 2016, p. 12).

7 Comunicación de la Comisión «Hacia una política global europea en materia de inversión internacional», $\operatorname{COM}(2010) 343$ final, p. 11. Resolución del Parlamento Europeo, 6 de abril de 2011, sobre la futura política europea en materia de inversiones 
las instituciones de la Unión han apostado por unos mecanismos ISDS renovados o "vanguardistas», aunque en la práctica la posición defendida durante estos últimos años ha demostrado ser algo errática y demasiado dada a la improvisación (Fach Gómez, 2017: 295-302; Fernández Rozas, 2015).

El cuestionamiento de los mecanismos ISDS también abarca una tercera dimensión: la de su compatibilidad con el ordenamiento jurídico de la Unión. Justamente, es esta la perspectiva que, vinculada a la necesidad de salvaguardar la autonomía del derecho de la Unión, aborda el presente trabajo. Efectivamente, se trata de un aspecto distinto al de la competencia, tal y como ha venido a señalar el TJUE en su Dictamen $2 / 15^{8}$, lo que le ha servido para evitar entrar a valorar un tema francamente complejo y, a su vez, comprometido. Un pronunciamiento en el que se declarara la incompatibilidad del mecanismo ISDS del TLCI UE-Singapur supondría una ruptura radical con la concepción actual del derecho de las inversiones extranjeras, donde el arbitraje desempeña un papel fundamental (Hindelang, 2013: 18). La renuncia (obligada) a estos mecanismos en los futuros TLCI de la Unión, por una parte, colocaría a la UE en una tesitura menos ventajosa ante los socios potenciales que abogan por su mantenimiento y, por otra, sería interpretada como un gran paso atrás desde la óptica de los inversores europeos, especialmente, en el marco de aquellos acuerdos que se pretendan celebrar con terceros Estados cuyos tribunales internos no ofrecen garantías de independencia.

En el momento actual, en primer lugar, es obligado señalar que el silencio del TJUE se acaba de romper, parcialmente, con la publicación de la sentencia en el asunto Achmea, el 6 de marzo de $2018^{9}$. La petición de decisión prejudicial dirigida al Tribunal de Justicia por el Bundesgerichtshof (Alemania) ${ }^{10}$ ha servido para que el TJUE, en contra de la posición del abogado general

extranjeras (2010/2203(INI)). Mandato del Consejo para la negociación del TTIP (Doc. ST 11103/13 Restreint UE/EU Restricted, de 17 de junio de 2013, Directrices de negociación relativas a la Asociación Transatlántica sobre Comercio e Inversión, entre la Unión Europea y los Estados Unidos de América, disponible en https://goo. gl/PZxM2h, párr. 23).

8 Dictamen 2/15 del Tribunal de Justicia de 16 de mayo de 2017, EU:C:2017:376, apdos. 30 y 290. Por otra parte, el deseo de limitar el pronunciamiento del TJUE a la cuestión relativa a la competencia se deduce claramente de la propia solicitud de dictamen cursada por la Comisión Europea (DO C 363, de 3 de noviembre de 2015, p. 18).

9 Sentencia del Tribunal de Justicia de 6 de marzo de 2018, Achmea, asunto C-284/16, EU:C:2018:158.

10 Petición de decisión prejudicial planteada por el Bundesgerichtshof (Alemania) el 23 de mayo de 2016, República de Eslovaquia / Achmea, asunto C-284/16 (DO 2016/C 296/25, de 16 de agosto de 2016). 
M. Wathelet ${ }^{11}$, haya declarado la incompatibilidad del arbitraje previsto en un APPRI intra-UE con el derecho de la Unión, de forma particular, con los arts. 267 y 344 del TFUE. Por tanto, se trata de un acontecimiento crucial, el primer hito que marcará el devenir del arbitraje de inversiones en la UE, ya que la decisión del TJUE impone, por de pronto, la necesidad de terminar o revisar los APPRI intra-UE todavía en vigor.

En segundo lugar, en cumplimiento del compromiso adoptado a nivel interno con la región belga de Valonia, en el contexto de las reticencias mostradas por esta región para la firma del CETA ${ }^{12}$, el Reino de Bélgica ha solicitado al TJUE una opinión sobre la compatibilidad del nuevo Sistema de Tribunales de Inversión previsto en el CETA con los tratados de la Unión ${ }^{13}$. Si bien esta decisión todavía está lejos de ser pronunciada y, por tanto, mantendrá durante un tiempo en vilo el proceso de ratificación del acuerdo, no cabe duda de que constituirá un segundo hito para el futuro de los mecanismos ISDS en la UE.

El presente trabajo trata de fijar cuáles son las coordenadas en las que se mueve el Tribunal para adoptar sus decisiones y cuáles son los argumentos a favor y en contra de la compatibilidad de estos mecanismos con el derecho de la Unión. En este sentido, las conclusiones del abogado general en el asunto Achmea, así como la propia sentencia del TJUE, son un buen indicador de las cuestiones relevantes del debate. Además, existe una amplia jurisprudencia del TJUE que marca las pautas a seguir y que sitúa la salvaguardia de la autonomía del ordenamiento jurídico de la Unión en el centro del debate relativo a la compatibilidad de los mecanismos ISDS.

Como punto de arranque del análisis que se abordará, interesa señalar que la compatibilidad de estos mecanismos no plantearía mayores problemas si se cumpliera alguna de las dos hipótesis siguientes: primera, considerar que los mecanismos ISDS se «integran» dentro del sistema jurisdiccional de la UE, y; segunda, apreciar que, en su condición de tribunales «externos» al sistema jurisdiccional de la UE, son tales sus características que no suponen una amenaza a

11 Las conclusiones del abogado general M. Wathelet en el asunto Achmea fueron presentadas el 19 de septiembre de 2017.

12 Véase el documento Déclaration du Royaume de Belgique relative aux conditions de pleins pouvoirs par l'Etat fédéral et les Entités fédérées pour la signature du CETA (disponible en: https://goo.gl/Dr3Ahk) que hizo posible finalmente superar el bloqueo impuesto por el Parlamento de Valonia, tal y como pone de manifiesto la Motion 633 (2016-2017), núm. 3, de 28 de octubre de 2016, «déposée en conclusion du débat sur l'Accord économique et commercial global (AECG-CETA)», disponible en: https:// goo.gl/igPwYK.

13 CETA. Belgian request for an opinion from the European Court of Justice, sometido al TJUE el 6 de septiembre de 2017, en https://goo.gl/gXbP13. 
la autonomía del ordenamiento jurídico de la Unión. A ello debería sumarse la constatación, conforme a los tratados de la Unión, del carácter no discriminatorio de estos mecanismos.

El presente trabajo comienza describiendo la realidad heterogénea y cambiante de los mecanismos ISDS en Europa, para, a continuación, centrarse en el análisis de la compatibilidad de los mismos desde la perspectiva de la autonomía del derecho de la Unión. Este estudio se aborda desde tres ángulos distintos: el primero, el que ofrece el art. 267 del TFUE y por el que se valora la posibilidad de considerar los tribunales de inversión como «órganos jurisdiccionales de un Estado miembro»; segundo, desde la perspectiva del art. 344 del TFUE se analiza si los mecanismos inversor-Estado quedan excluidos de su ámbito de aplicación y; tercero, como antesala de las conclusiones que se encargan de cerrar el trabajo, desde el enfoque más general que ofrece el art. 19.1 TUE se cuestiona si los tribunales de inversión socavan las características específicas de la Unión y de su derecho.

\section{LOS MECANISMOS ISDS EN LA UNIÓN EUROPEA: UNA REALIDAD HETEROGÉNEA Y CAMBIANTE}

Aunque quizás sea afirmar lo obvio, cuando nos referimos a los mecanismos ISDS como una realidad heterogénea y cambiante, lo primero que interesa destacar es que se trata de una «realidad». Es, pues, una realidad que, por otra parte, no es nueva para Europa. Muy al contrario, el arbitraje de inversiones, desde hace varias décadas, está muy presente en los Estados miembros a raíz de la firma de los APPRI, sin olvidar el Tratado de la Carta de la Energía, que también lo prevé y en el que, junto a todos los Estados miembros, salvo Italia $^{14}$, la propia UE participa como parte del tratado ${ }^{15}$. Además, sobre la base de estos tratados se han desarrollado numerosos procedimientos arbitrales, entre los que no faltan aquellos que resuelven controversias intra-UE ${ }^{16}$, es decir, litigios que enfrentan a un Estado miembro con inversores de otro

14 Italia denunció el Tratado de la Carta de la Energía el 31 de diciembre de 2014, siendo esta denuncia efectiva desde el 1 de enero de 2016.

15 Decisión 98/181/CE, CECA y Euratom del Consejo y de la Comisión, de 23 de septiembre de 1997, relativa a la conclusión, por parte de las Comunidades Europeas, del Tratado sobre la Carta de la Energía y el Protocolo de la Carta de la Energía sobre la eficacia energética y los aspectos medioambientales relacionados, DO L 69 de 9 de marzo de 1998.

16 Según pone de relieve UNCTAD (2017: 2), el número total de arbitrajes de inversión intra-UE conocidos, a 31 de julio de 2017 , era de 153 , lo que supone el $19 \%$ de los casos conocidos globalmente. 
Estado miembro, donde han estado muy presentes argumentos de derecho de la Unión y donde, incluso, la propia Comisión ha tenido ocasión de participar como amicus curiae ${ }^{17}$.

Esta realidad abrumadora es, al mismo tiempo, heterogénea. No existe un único modelo de tribunal de inversión. En primer lugar, el arbitraje de inversiones puede tener origen contractual o convencional; es decir, puede ser resultado del consentimiento previsto en un contrato o de la oferta (consentimiento estatal) incorporada en un tratado de inversiones. En segundo lugar, puede tratarse de un arbitraje ad hoc o un arbitraje institucional. En tercer lugar, dadas sus características específicas de autonomía y exclusividad, este puede ser un arbitraje del Centro Internacional de Arreglo de Diferencias relativas a Inversiones (CIADI) u otro arbitraje, bien institucional o ad hoc conforme a las reglas de arbitraje de la CNUDMI, caracterizado por una mayor participación e influencia de los tribunales internos durante las distintas fases de su desarrollo. En cuarto lugar, cuando la opción del arbitraje de inversiones venga recogida en un APPRI, este puede presentarse como la única vía de recurso disponible para el inversor, como una opción alternativa a los tribunales internos o, incluso, como una vía complementaria y posterior a la de los tribunales internos del Estado. En quinto lugar, según las previsiones recogidas en el contrato o el APPRI que da origen al arbitraje, este puede ser un arbitraje limitado a resolver la disputa en el marco de un derecho estatal, un arbitraje referido exclusivamente a la violación del propio tratado o bien llamado a resolver aplicando el tratado, otras normas y principios del derecho internacional y las normas del Estado que sea parte en la diferencia. En sexto lugar, los arbitrajes de inversión pueden ser intra-UE o extra-UE, aspecto que para el análisis de su compatibilidad puede resultar crucial.

A toda esta variedad de modelos de arbitraje inversor-Estado que engloba la concepción clásica o tradicional del arbitraje de inversiones se han de sumar las nuevas propuestas que la UE está realizando en el marco de su nueva política de inversiones extranjeras (Burgstaller, 2012: 208-221; Fach Gómez, 2017: 295-302; Fernández Masiá, 2017: 155-173; Pascual Vives, 2017a: 175200; Pascual Vives, 2017b: 287-294). Estas propuestas son prueba fehaciente de una realidad «cambiante» que incrementa la inseguridad y que hace que uno llegue a preguntarse si es posible vaticinar cuándo llegará el día en el

17 Eureko B.V. c. República de Eslovaquia, Corte Permanente de Arbitraje, caso núm. 2008-13 (hoy, Achmea); European American Investment Bank AG (EURAM) c. República de Eslovaquia, Corte Permanente de Arbitraje, caso núm. 2010-17; Isolux c. España, Instituto de Arbitraje de la Cámara de Comercio de Estocolmo, caso núm. V2013/153. Véase Dias Simóes (2017: 233-303). 
que pueda darse por cerrado el debate en torno a la compatibilidad de los mecanismos ISDS.

Así, el Acuerdo entre la UE y Singapur propone un modelo de arbitraje de inversiones renovado que incorpora elementos que pueden resultar relevantes en aras a asegurar su compatibilidad con el ordenamiento jurídico de la Unión. Por su parte, el Sistema de Tribunales de Inversión, propuesto en el marco de las negociaciones del TTIP y posteriormente, incluido en el CETA y en el TLCI de la UE y Vietnam, inaugura un modelo que bien podría considerarse como el primer gran paso hacia un nuevo paradigma de los mecanismos ISDS ${ }^{18}$. Este original modelo, pero de equívoca naturaleza (Iruretagoiena Agirrezabalaga, 2017b: 84-88), incorpora varios elementos claramente dirigidos a salvaguardar su compatibilidad con el derecho de la Unión, mas está por ver si serán suficientes para satisfacer tal propósito. Asimismo, si bien no deja de ser una propuesta de futuro, como paso definitivo hacia el cambio de paradigma, la UE ha hecho de la iniciativa de un Tribunal Multilateral de Inversiones (MIC, en su acrónimo en inglés) su bandera; sin embargo, más allá de las que pueda sugerir su propia denominación, está por ver cuáles serán las características concretas que definan este tribunal (Fernández Masiá, 2015). Por último, no cabe descartar un mecanismo ISDS futuro para las controversias de inversión intra-UE, tal y como han llegado a proponer algunos Estados miembros ${ }^{19}$, como respuesta a los requerimientos de la Comisión para que den término a sus respectivos APPRI intra-UE ${ }^{20}$.

Este breve inventario de la diversidad de modelos que incluye el concepto de mecanismo ISDS sirve para advertir de que no puede existir una única respuesta a la pregunta de por qué los mecanismos ISDS son o no son

18 Propuesta de la Comisión, hecha pública el 16 de septiembre de 2015, para ser discutida a nivel interno, en el marco de las negociaciones del TTIP, y que posteriormente se incorpora al CETA (Joint statement Canada-EU Comprehensive Economic and Trade Agreement [CETA], 29 de febrero de 2016, disponible en https://goo.gl/sUhgSC). Véanse Díez-Hochleitner (2015: 5-7); Fach Gómez (2016: 189-224). Para una visión crítica de la posición adoptada por la Comisión, véase Brower, 2015: 653-686.

19 En este sentido, en un documento que Austria, Finlandia, Francia, Alemania y los Países Bajos han presentado ante el Comité de Política Comercial del Consejo, se aboga por la sustitución de los APPRI intra-UE por un único acuerdo intra-UE que prevea mecanismos ISDS; este documento, que ha sido filtrado por la red «Seattle to Brussels», se encuentra disponible en https://goo.gl/waEpMR. Véase también, el informe anual del CEF, 2013, doc. ST17899 2013 INIT, párr. 18, o el informe anual del CEF, 2014, doc. ST 69352015 INIT, párr. 18.

20 Comunicado de Prensa de la Comisión, de 18 de junio de 2015, disponible en: https://goo.gl/RXSMaE. 
compatibles con el ordenamiento jurídico de la Unión. Y es así como lo entiende, por ejemplo, la propia Comisión Europea cuando, al mismo tiempo, defiende que el arbitraje inversor-Estado acordado entre dos Estados miembros (arbitraje intra-UE) es contrario al derecho de la Unión ${ }^{21}$ —opinión que hoy, tras la sentencia del caso Achmea, es respaldada por el TJUE_, tolera el arbitraje previsto en los APPRI que vinculan a los Estados miembros con terceros Estados (arbitrajes extra-UE) ${ }^{22}$ y actúa como principal valedor de los mecanismos ISDS en el marco de los TLCI de nueva generación.

\section{LA COMPATIBILIDAD DE LOS MECANISMOS ISDS DESDE LA PERSPECTIVA DE LA AUTONOMÍA DEL ORDENAMIENTO JURÍDICO DE LA UNIÓN EUROPEA}

\section{ASPECTOS GENERALES DE LA PROBLEMÁTICA: CARTOGRAFÍA DE UN TERRENO PANTANOSO}

Desde la perspectiva del derecho de la Unión el debate sobre la compatibilidad de los mecanismos ISDS afecta directamente a la cuestión de la autonomía del ordenamiento jurídico de la UE. La noción de autonomía encuentra su origen en los celebérrimos asuntos Van Gend en Loos y Costa/ENEL (Van Rossem, 2013: 15). Cuando el Tribunal de Justicia se refiere a la Comunidad como "un nuevo ordenamiento jurídico de derecho internacional», pone de manifiesto la necesidad de "garantizar la unidad de interpretación» del derecho comunitario, lo que le lleva a reconocer a sus normas efecto directo $^{23}$ y primacía respecto a las normas internas de los Estados miembros ${ }^{24}$.

21 Véase Comunicación de la Comisión Europea, C(2017) 7384 final, de 10 de noviembre de 2017, Ayuda de Estado SA.40348 (2015/NN), párr. 160.

22 El Reglamento (UE) 1219/2012, del Parlamento Europeo y del Consejo, de 12 de diciembre de 2012, por el que se establecen disposiciones transitorias sobre los acuerdos bilaterales de inversión entre Estados miembros y terceros países, constituye sin duda una evidencia de esta posición.

23 Sentencia del Tribunal de Justicia de 5 de febrero de 1963, Van Gend en Loos, asunto 26/62, EU:C:1963:1.

24 Sentencia del Tribunal de Justicia de 15 de julio de 1964, Costa / ENEL, asunto 6/64, EU:C:1964:66. Lo contrario equivaldría a poner «en tela de juicio la base jurídica misma de la Comunidad». Estas conclusiones han sido posteriormente reafirmadas por el TJUE en distintos pronunciamientos. Por ejemplo, Dictamen 1/91 del Tribunal de Justicia de 14 de diciembre de 1991, EU:C:1991:490, apdo. 21; Dictamen 1/09 del Tribunal de Justicia de 8 de marzo de 2011, EU:C:2011:123, apdo. 65; Dic- 
La eficacia del derecho de la Unión y, por tanto, la realización de los objetivos previstos en el mismo depende de que sus normas sean interpretadas y aplicadas de manera uniforme en todos los Estados miembros, sin que sea posible oponer ninguna norma interna, ni siquiera de rango constitucional, para justificar una interpretación particular o para evitar su aplicación (Van Rossem, 2013: 15).

El concepto de autonomía, que en estas primeras decisiones se refiere a la relación entre el derecho de la Unión y los derechos internos de los Estados miembros (Herrmann, 2014: 581-582; Hindelang, 2013: 189-192), tras un largo período de ausencia, reaparece en el Dictamen 1/91 del TJUE (Van Rossem, 2013: 15), esta vez para ordenar la relación entre el ordenamiento jurídico de la Unión y el derecho internacional y, en particular, la compatibilidad de los tribunales externos al sistema jurisdiccional previsto en los tratados de la Unión con el derecho de la UE ${ }^{25}$. Esta decisión del TJUE ha precedido a otras no menos importantes, como son el Dictamen $1 / 00^{26}$, el Dictamen $1 / 09^{27}$ y el último y especialmente polémico Dictamen $2 / 13^{28}$, sin olvidar la sentencia dictada en el asunto Mox Plant ${ }^{29}$. Todas ellas, a las que obviamente debemos sumar la sentencia del TJUE en el asunto Achmea, han ido progresivamente delimitando el significado de la autonomía del ordenamiento jurídico de la UE en relación con la posibilidad de someter diferencias a tribunales externos a la Unión. Además, el TJUE, mediante la sentencia Kadi y Al Barakaat, ha impreso a la noción de autonomía un significado que reconoce al derecho de

tamen 2/13 del Tribunal de Justicia de 18 de diciembre de 2014, EU:C:2014:2454, apdos. 157 y 166.

25 Dictamen 1/91 del Tribunal de Justicia de 14 de diciembre de 1991, EU:C:1991:490. El dictamen se refería al Tribunal del Espacio Económico Europeo. Véase al respecto, Martín y Pérez de Nanclares (2011: 254-286); Van Rossem (2013: 13-46).

Dictamen 1/00 del Tribunal de Justicia de 18 de abril de 2002, EU:C:2002:231, sobre la compatibilidad del sistema de vigilancia jurisdiccional previsto en el Proyecto de Acuerdo referente a la creación del Espacio Europeo Aéreo Común entre la Comunidad Europea y países terceros (Acuerdo EEAC).

27 Dictamen 1/09 del Tribunal de Justicia de 8 de marzo de 2011, EU:C:2011:123, relativo al Sistema Unificado de Resolución de Litigios sobre Patentes.

28 Dictamen 2/13 del Tribunal de Justicia de 18 de diciembre de 2014, EU:C:2014:2454, sobre el proyecto de acuerdo por el que la UE pretendía adherirse al Convenio Europeo de Derechos Humanos (CEDH).

29 Sentencia del Tribunal de Justicia de 30 de mayo de 2006, Comisión/Irlanda, asunto C-459/03, EU:C:2006:345, relativa a la compatibilidad del arbitraje entre Estados miembros en el marco de la Convemar (Convención de las Naciones Unidas sobre el Derecho del Mar, de 16 de noviembre de 1994 [U.N.T.S. vol. 1834, p. 371]). 
la Unión una dimensión constitucional e intensifica, aún más si cabe, la preocupación por su integridad ${ }^{30}$.

En virtud del art. 19.1 TUE, corresponde al TJUE y los tribunales de los Estados miembros salvaguardar la autonomía del ordenamiento jurídico de la $\mathrm{UE}^{31}$. El sistema jurisdiccional construido por los tratados de la Unión se fundamenta, por tanto, en la colaboración entre los tribunales internos de los Estados miembros y el TJUE ${ }^{32}$. Por su parte, la piedra angular que sostiene este edificio jurisdiccional, en tanto que cauce principal para desarrollar dicha cooperación, es el procedimiento de remisión prejudicial previsto en el art. 267 TFUE (Alonso García, 2014: 9-27) 33.

La propia competencia del TJUE, como garante de la autonomía en un sistema jurisdiccional centralizado, manifestada en el art. 19.1 TUE y los arts. 344 y 267 TFUE, es considerada como parte de las características específicas del ordenamiento jurídico de la UE, es decir, de la propia autonomía, que el Tribunal debe preservar ${ }^{34}$. Por todo ello, la clave de la compatibilidad radica en determinar si el sometimiento a un mecanismo ISDS externo supone o no socavar las características específicas de la Unión y de su derecho, incluida la competencia del TJUE para desempeñar la función «constitucional» asignada en los tratados (Eeckhout, 2015: 958; Gáspár-Szilágyi, 2016: 704-708; Schill, 2013: 37-54).

$\mathrm{Y}$ es en este punto donde resulta pertinente valorar y poner de manifiesto la actitud que ha mostrado el TJUE frente a tribunales externos en las ocasiones que ha tenido que pronunciarse (Lavranos, 2013: 205-215; Lavranos,

30 Sentencia del Tribunal de Justicia de 3 de septiembre de 2008, Kadi y Al Barakaat, asuntos acumulados C402/05 P y C415/05, EU:C:2008:461. Véase Van Rossem (2013: 14-17).

31 Dictamen 1/91 del Tribunal de Justicia de 14 de diciembre de 1991, EU:C:1991:490, apdo. 35; Dictamen 2/13 del Tribunal de Justicia de 18 de diciembre de 2014, EU:C:2014:2454, apdos. 174-175. En el mismo sentido, Conclusiones del abogado general M. Wathelet, 19 de septiembre de 2017, Achmea, asunto C284/16, EU:C:2017:699, punto 234 .

32 Tal y como ha señalado el Tribunal de Justicia en el Dictamen 1/09 del Tribunal de Justicia de 8 de marzo de 2011, EU:C:2011:123, apdos. 66, 68 y 69. Sobre el papel fundamental que cumplen los tribunales internos dentro del sistema jurisdiccional contemplado en los tratados, véase Baratta (2011: 297-320).

33 Dictamen 2/13 del Tribunal de Justicia de 18 de diciembre de 2014, EU:C:2014:2454, apdo. 176.

34 Ibid., apdo. 183; Sentencia del Tribunal de Justicia de 3 de septiembre de 2008, Kadi y Al Barakaat, asuntos acumulados C402/05 P y C415/05, EU:C:2008:461, apdo. 282. Véase Herrmann (2014: 573). 
2010: 393-411; Schmalenbach, 2008: 145-168). El TJUE ha hecho gala de un excesivo celo en la defensa de sus funciones, una actitud que se ha visto reflejada en una jurisprudencia que, con el trascurso del tiempo, ha ido gradualmente estrechando el cerco, elevando el nivel de exigencia en cuanto a las condiciones que debe reunir un tribunal externo para poder ser considerado compatible con el derecho de la Unión, hasta llegar a su expresión más radical en el Dictamen 2/13, relativo al proyecto de acuerdo por el que la UE pretendía adherirse al Convenio Europeo de Derechos Humanos (CEDH) (Martín y Pérez de Nanclares, 2015: 825-869; Zelazna, 2017: 91-93 y 95-96). Ello le ha servido al Tribunal de Justicia para que algunos autores le recuerden que «la autonomía no es igual que autismo» (Martín y Pérez de Nanclares, 2015: 833) o que la Opinión $2 / 13$ se fundamenta en un concepto de autonomía del derecho de la UE que linda con la autarquía ${ }^{35}$. En cualquier caso, la jurisprudencia del TJUE, hoy por hoy, dibuja un escenario complicado para cualquier tribunal externo que pretenda extender su jurisdicción al espacio europeo y, en consecuencia, también para los mecanismos ISDS (Schill, 2015: 379-388; Lenk, 2017: 135-162).

Dicho lo anterior, no sería razonable cuestionar la legitimidad, ni la necesidad, del control que realiza el TJUE al exigir a los mecanismos de solución de controversias externos el respeto de la autonomía del derecho de la Unión $y$, por ende, el respeto de sus elementos esenciales. No obstante, sin renunciar a esta lícita aspiración, quizás es el momento de hacer una nueva lectura más abierta y flexible de esta autonomía, de forma que sea más propicia a un diálogo real entre distintos tribunales internacionales (Eeckhout, 2015: 963) y, por tanto, más adecuada a los tiempos actuales de proliferación de tribunales internacionales e incremento de la cooperación internacional (Schill, 2013: 43. Lavranos, 2010: 394-395; Govaere, 2010: 187-207).

\section{TRIBUNALES DE INVERSIÓN COMO «ÓRGANOS JURISDICCIONALES DE UN ESTADO MIEMBRO»}

Una primera fórmula para salvaguardar la autonomía del derecho de la Unión consiste en considerar los tribunales de inversión como "órganos jurisdiccionales de un Estado miembro", es decir, integrar los mecanismos ISDS dentro de la arquitectura jurisdiccional prevista en los tratados, de modo que puedan (o, en su caso, deban) valerse del procedimiento de remisión prejudicial previsto en el art. 267 TFUE (Basedow, 2015: 367-386; Rovetta,

35 Eeckhout (2015: 992): «Opinion 2/13 is based on a concept of the autonomy of EU Law which borders on autarky». 
2013: 227-228) ${ }^{36}$. Tal y como ha señalado el abogado general en el asunto Achmea, considerar a los tribunales de inversión parte del sistema jurisdiccional de los Estados miembros que los hayan creado supondría incorporarles al diálogo jurisdiccional previsto en el art. 267 TFUE, pero, también, imponerles la obligación de aplicar el derecho de la Unión atendiendo a los principios de primacía, efecto directo y confianza mutua ${ }^{37}$. Además, en caso de que estos tribunales de inversión no aplicaran o aplicaran de forma defectuosa el derecho de la Unión, la responsabilidad por dicho incumplimiento recaería en el Estado miembro correspondiente ${ }^{38}$. Incluso, cabría la posibilidad de iniciar un procedimiento por incumplimiento contra ese Estado miembro sobre la base de los arts. 258 y 259 TFUE.

Sin embargo, ¿es posible plantearse seriamente la posibilidad de considerar a los mecanismos ISDS como órganos jurisdiccionales de un Estado miembro? Atendiendo a las características de los distintos modelos ISDS presentes, el arbitraje previsto en los APPRI intra-UE es, quizás, el que mejor se presta a una calificación en tal sentido. Este ha sido el caso, por ejemplo, en el asunto Achmea, donde la controversia traía causa del arbitraje iniciado en el marco del APPRI Países Bajos-Eslovaquia, con sede en Fráncfort, desarrollado conforme a las reglas de arbitraje de la CNUDMI y con la Corte Permanente de Arbitraje realizando las funciones de secretaría ${ }^{39}$.

Existe una amplia jurisprudencia del TJUE que, en respuesta a una casuística muy variada, identifica los elementos que deben considerarse para que un mecanismo de arreglo de diferencias pueda ser considerado «órgano jurisdiccional» a los efectos del art. 267 TFUE (Cienfuegos Mateo, 2014: 28-43; Soca Torres, 2015). Según esta jurisprudencia, que arranca con la decisión en el asunto Vaassen-Göebbels ${ }^{40}$ y es modulada y desarrollada en decisiones posteriores (Rodríguez Medal, 2015: 110-118), resulta necesario tomar en consideración las siguientes características: «El origen legal del organismo, su permanencia, el carácter obligatorio de su jurisdicción, el carácter

36 Tal y como ha señalado el TJUE en la Sentencia de 6 de marzo de 2018, Achmea, asunto C-284/16, EU:C:2018:158, apdo. 43, ello permitiría asegurar la plena eficacia de las normas de la Unión.

37 Conclusiones del abogado general M. Wathelet, 19 de septiembre de 2017, Achmea, asunto C284/16, EU:C:2017:699, puntos 133-134.

38 Sentencia del Tribunal de Justicia de 30 de septiembre de 2003, Köbler, asunto C-224/01, EU:C:2003:513.

39 Anteriormente, Eureko B.V. c. República de Eslovaquia, Corte Permanente de Arbitraje, caso núm. 2008-13.

40 Sentencia del Tribunal de Justicia de 30 de junio de 1966, Vaassen-Goebbels, asunto 61/65, EU:C:1966:39. 
contradictorio del procedimiento y la aplicación por parte del organismo de normas jurídicas, así como su independencia ${ }^{41}$. Sin embargo, a pesar de la identificación de estos criterios, la noción de órgano jurisdiccional sigue siendo un concepto de contornos imprecisos, expuesto, en cada caso, a interpretaciones divergentes ${ }^{42}$.

Por lo que interesa al presente trabajo, cabe señalar que los tribunales arbitrales han estado, por lo general, excluidos del concepto de órgano jurisdiccional del art. 267 TFUE, desde que en el asunto Nordsee del año 1982 el Tribunal de Justicia indicara, por una parte, que las partes en el procedimiento arbitral eran libres de someter el arreglo de sus diferencias a los tribunales ordinarios o de elegir la vía arbitral y, por tanto, «no tenían ninguna obligación, de hecho o de Derecho, de confiar sus diferencias al arbitraje» y, por otra, que «las autoridades públicas [...] no estaban implicadas en la elección de la vía arbitral», que se había hecho mediante contrato, no pudiendo, además, intervenir de oficio en el desarrollo del procedimiento arbitral ${ }^{43}$. Del pronunciamiento del TJUE en el asunto Nordsee se puede concluir que el arbitraje no llega a satisfacer los criterios relativos al origen legal y al carácter obligatorio de la jurisdicción que requiere todo órgano jurisdiccional a los efectos del art. 267 TFUE.

Sin embargo, por una parte, es pertinente tener en cuenta que el arbitraje de inversiones presenta rasgos propios que lo diferencian y alejan del modelo comercial, lo que puede exigir un análisis diferenciado (Hindelang,

41 Sentencia del Tribunal de Justicia de 12 de junio de 2014, Ascendi Beiras Litoral e Alta, asunto C-377/13, EU:C:2014:1754, apdo. 23. En el mismo sentido, entre otras, Sentencia del Tribunal de Justicia de 31 de enero de 2013, Belov, asunto C-394/11, EU:C:2013:48, apdo. 38; Sentencia del Tribunal de Justicia de 14 de junio de 2011, Miles y otros, asunto C-196/09, EU:C:2011:388, apdo. 37; Sentencia del Tribunal de Justicia de 22 de diciembre de 2010, Koller, asunto C118/09, EU:C:2010:805, apdo. 22. Véanse también las recomendaciones del TJUE «a los órganos jurisdiccionales nacionales, relativas al planteamiento de cuestiones prejudiciales», DO C 338, de 2 de noviembre de 2012, p. 2.

42 En este sentido, las apreciaciones realizadas por el abogado general Dámaso Ruiz-Jarabo Colomer en sus conclusiones presentadas el 28 de junio de 2001, François De Coster, asunto C-17/00, EU:C:2001:366, punto 14.

43 Sentencia del Tribunal de Justicia de 23 de marzo de 1982, Nordsee, asunto C-102/81, EU:C:1982:107, apdos. 12 y 13. En la misma línea, por ejemplo, la Sentencia del Tribunal de Justicia de 27 de enero de 2005, Denuit Cordenier, asunto C-125/04, EU:C:2005:69, apdos. 13-16. Véase, para una visión general, Sánchez Rodríguez (2013). Una valoración crítica de la decisión en Nordsee se encuentra en Basedow (2015: 369-371). 
2012: 201-203; Olík y Fyrbach, 2011: 191-205). Por otra parte, casos más recientes parecen apuntar hacia una cierta flexibilización o apertura del concepto de órgano jurisdiccional en relación con tribunales de naturaleza arbitral. Así, resultan especialmente relevantes las decisiones en los asuntos Merck Canada ${ }^{44}$ y Ascendi Beiras Litoral e Alta ${ }^{45}$. En ambos casos, tribunales arbitrales han sido considerados como órganos jurisdiccionales de Portugal tras tomar en consideración las particularidades presentes: el origen legal de los tribunales arbitrales y el carácter obligatorio de su jurisdicción ${ }^{46}$.

¿Cabría extrapolar la misma conclusión al arbitraje instituido sobre la base de un tratado de inversiones intra-UE? En atención al origen legal, bien por estar previsto en un APPRI o en una ley interna, del arbitraje de inversiones y el carácter obligatorio que adquiere la jurisdicción arbitral para el Estado una vez el tratado de inversiones entra en vigor, se podría concluir, efectivamente, que el arbitraje de inversiones reúne todas las características mencionadas en la reiterada jurisprudencia del Tribunal de Justicia (Basedow, 2015: 376-381; Rovetta, 2013: 227). Esta apreciación, además, se vería reforzada tras la sentencia dictada en el asunto Ascendi Beiras Litoral e Alta, donde el requisito del carácter obligatorio de la jurisdicción arbitral se ha visto satisfecho en un supuesto en el que el demandante podía optar entre acudir al Tribunal Arbitral Tributário o a los tribunales ordinarios ${ }^{47}$. No obstante, aun

44 Auto del Tribunal de Justicia de 13 de febrero de 2014, Merck Canada, asunto C-555/13, EU:C:2014:92.

45 Sentencia del Tribunal de Justicia de 12 de junio de 2014, Ascendi Beiras Litoral e Alta, asunto C-377/13, EU:C:2014:1754.

46 Ibid., apdo. 24; Auto del Tribunal de Justicia de 13 de febrero de 2014, Merck Canada, asunto C-555/13, EU:C:2014:92, apdo. 19. Véase Pereira Coutinho (2015: 235-260); Paschalidis (2017: 663-685).

47 Sentencia del Tribunal de Justicia de 12 de junio de 2014, Ascendi Beiras Litoral e Alta, asunto C-377/13, EU:C:2014:1754, apdo. 29. En el mismo sentido se expresó anteriormente el TJUE en los asuntos Emanuel (Sentencia del Tribunal de Justicia de 6 de octubre de 1981, asunto C-259/04, EU:C:2006:215) y Broekmeulen (Sentencia del Tribunal de Justicia de 30 de marzo de 2006, asunto C-246/80, EU:C:1981:218). La decisión de Ascendi Beiras Litoral e Alta se aleja, aunque se sirve de ellos como precedente, de otras decisiones del TJUE en las que ha considerado admisibles las cuestiones prejudiciales planteadas por un tribunal arbitral, cuando la vía arbitral constituía la única vía disponible, obligatoria, por tanto, para quien instaba la reclamación. Por ejemplo, la Sentencia del Tribunal de Justicia de 17 de octubre de 1989, Handelsog Kontorfunktionærernes Forbund i Danmark, asunto C-109/88, EU:C:1989:383, apdo. 7 y el Auto del Tribunal de Justicia de 13 de febrero de 2014, Merck Canada, asunto C-555/13, EU:C:2014:92, apdos. 19-20. Se ha de señalar, no obstante, que el 
habiendo razones de peso en tal sentido, considero que tal conclusión supone ir demasiado lejos, hasta el punto de pervertir la esencia misma del arbitraje de inversiones, a saber, su carácter consensual.

Pero no es esta, quizás, la razón principal que conduce a rechazar que los tribunales arbitrales intra-UE puedan servirse del recurso previsto en el art. 267 TFUE. Para que un órgano jurisdiccional pueda presentar una cuestión prejudicial es necesario que este sea «de un Estado miembro» (o «nacional») (Von Papp, 2013: apdo. 8.1.4). Esta ha sido la razón por la cual prácticamente se ha descartado desde el principio del presente epígrafe cualquier posibilidad de considerar los mecanismos ISDS previstos en acuerdos celebrados con terceros Estados como órganos jurisdiccionales de un Estado miembro ${ }^{48}$. Difícilmente pueden ser considerados de un Estado miembro mecanismos ISDS creados junto a terceros Estados, y que tienen la clara vocación de actuar como autoridades externas (internacionales o transnacionales) en sustitución de los tribunales internos de los respectivos Estados. ¿Y qué decir de los mecanismos ISDS previstos en los TLCI en los que, junto a los propios Estados miembros, es la propia UE quien participa en su creación, y cuando esos mismos tratados son los que reconocen la naturaleza internacional del mecanismo ${ }^{49}$ ? En cualquier caso, parece evidente que para que un tribunal de inversiones previsto en un tratado celebrado con terceros Estados pueda plantear cuestiones prejudiciales y quede, de esta forma, sometido a la autoridad del TJUE y obligado a aplicar el derecho de la Unión conforme a los principios de primacía y efecto directo, será necesario, no solo un consentimiento expreso de ese tercer Estado, sino también la modificación del art. 267 TFUE.

carácter obligatorio de la jurisdicción también se ha relacionado en algún caso con los efectos de las decisiones; en este sentido, el auto del Tribunal de Justicia en el asunto Merck Canada, apdos. 19, considera relevante a esos efectos el hecho de que las decisiones del tribunal arbitral producen «los mismos efectos que las resoluciones dictadas por los órganos jurisdiccionales ordinarios». Véanse Von Papp (2013: epígrafe 8.1.2); García Antón (2015: 517-518).

En este sentido, en contra de lo que se apuntó en el arbitraje Iron Rinhe (Corte Permanente de Arbitraje, caso núm. 2003-02, Bélgica/Países Bajos, párr. 103), considero que los tribunales internacionales no se encuentran en una posición análoga a la de los tribunales internos. Véase Lock (2015: 145). Sobre la cuestión prejudicial y las jurisdicciones internacionales véase Cienfuegos Mateo (2012: 151-192).

49 La naturaleza internacional del arbitraje de inversiones previsto en el TLCI de la UE y Singapur se deduce del art. 9.17 del acuerdo. Además, hay autores que señalan que la jurisdicción del Sistema de Tribunales de Inversión no es ni obligatoria ni exclusiva; véase Gáspár-Szilágyi (2016: 736). 
Volviendo a los arbitrajes que encuentran su origen en APPRIs intra-UE, es necesario, en primer lugar, poner de manifiesto la diferencia existente entre un arbitraje de inversión y los arbitrajes tributarios de los asuntos Merck Canada y Ascendi Beiras Litoral e Alta, en aras a señalar la dificultad de extender la conclusión alcanzada en los mismos al arbitraje de inversiones. En estos dos últimos casos, resulta evidente la integración del arbitraje en el sistema jurisdiccional de Portugal. Así, en cuanto al Tribunal Arbitral Tributário del asunto Ascendi Beiras Litoral e Alta cabe señalar que este se integra claramente dentro del sistema jurisdiccional de Portugal, constituyendo una pieza más de la estructura de tribunales encargada de administrar justicia en el país ${ }^{50}$. Así lo indica expresamente la Constitución portuguesa en su art. 209.2, cuando prevé la posibilidad de crear tribunales arbitrales ${ }^{51}$. Por su parte, el Decreto Ley portugués 10/2011, regulador del régimen jurídico del arbitraje en materia tributaria, en su art. 25 abre la posibilidad (aunque limitada) para la presentación de recursos, tanto ante el Tribunal Constitucional como ante el Supremo Tribunal Administrativo. Además, como reconocimiento del carácter nacional del arbitraje, el preámbulo del decreto ley afirma que la decisión arbitral puede ser objeto de remisión prejudicial de conformidad con el art. 267 TFUE. Por último, resulta relevante destacar que la finalidad del arbitraje tributario no es actuar como un tribunal externo al sistema jurisdiccional nacional ante las dudas que este puede generar en relación con su neutralidad o independencia, sino la de servir al objetivo de agilizar y simplificar los procedimientos en materia tributaria ${ }^{52}$. Todos estos elementos, que, por otra parte, no se encuentran en el arbitraje de inversiones, pueden justificar una interpretación más flexible de los requisitos establecidos por el TJUE, de forma particular, el de la obligatoriedad de la jurisdicción arbitral, que en situaciones normales debería interpretarse como la disponibilidad de una única vía (la arbitral) para dar curso a una reclamación.

Puede que la mejor fórmula, aunque también insuficiente tal y como, por otra parte, ha venido a señalar el TJUE en $A c h m e a^{53}$, para abrir el art.

50 Esta diferencia ha sido tenida en cuenta por el TJUE en la Sentencia del Tribunal de Justicia de 6 de marzo de 2018, Achmea, asunto C-284/16, EU:C:2018:158, apdo. 44.

51 El art. 209 se integra dentro del título V de la Constitución dedicado a los tribunales y donde el art. 202.1 señala que los tribunales son los órganos de soberanía con competencia para administrar la justicia en nombre del pueblo.

52 Este aspecto es puesto de relieve en las conclusiones del abogado general Maciej Szpunar, de 8 abril de 2014, Ascendi Beiras Litoral e Alta, asunto C-377/13, EU:C:2014:246, punto 50 .

53 Sentencia del Tribunal de Justicia de 6 de marzo de 2018, Achmea, asunto C-284/16, EU:C:2018:158, apdo. 48. 
267 TFUE a los tribunales de inversión intra-UE consista en reconocerles la condición de órgano jurisdiccional «común» a dos Estados miembros. Es lo que proponía, por ejemplo, el abogado general en el asunto $A c h m e a^{54}$ y fue la argumentación que sirvió al TJUE para permitir al Tribunal de Justicia de Benelux recurrir al procedimiento de remisión prejudicial en el asunto Parfums Christian Dior ${ }^{5}$. Sin embargo, este mismo argumento no resultó suficiente para que el TJUE reconociera a la Sala de Recursos de las Escuelas europeas la facultad de plantear cuestiones prejudiciales. Y ello porque, según el Tribunal, entre otros motivos, la Sala de Recursos no presentaba vínculos con los sistemas jurisdiccionales de los Estados miembros, a diferencia de lo que ocurría en el Tribunal de Justicia de Benelux ${ }^{56}$. Así, el procedimiento que se desarrolla ante el Tribunal de Benelux constituye un incidente en los procesos pendientes ante los órganos jurisdiccionales nacionales y sirve al objetivo de establecer la interpretación definitiva de las normas jurídicas comunes a los tres Estados del Benelux y, por tanto, puede considerase como una pieza más del engranaje jurisdiccional nacional de los tres Estados ${ }^{57}$.

¿Cuáles son los vínculos existentes entre los tribunales arbitrales constituidos a partir de las previsiones de los APPRI intra-UE y el sistema jurisdiccional de los Estados miembros? Sinceramente, estas no son fáciles de adivinar, incluso en aquellos supuestos en los que el arbitraje establezca su sede en uno de los dos Estados miembros partes en el APPRI (Reinisch, 2013: 156). Es lo que el TJUE ha concluido en el asunto Achmea al afirmar que un arbitraje de inversiones intra-UE «no presenta tales vínculos con los sistemas jurisdiccionales de los Estados miembros», descartando, así, la posibilidad de considerarlo como un órgano jurisdiccional común a varios Estados miembros $^{58}$. No obstante, la posibilidad de crear un tribunal común a los Estados miembros abierta por la decisión en el asunto Parfums Christian Dior puede ser aprovechada si, tal y como proponen algunos Estados miembros, se decide crear, en el futuro, un mecanismo ISDS intra-UE que sirva para sustituir la

54 Conclusiones del abogado general M. Wathelet, 19 de septiembre de 2017, Achmea, asunto C284/16, EU:C:2017:699, puntos 84-131.

55 Sentencia del Tribunal de Justicia de 4 de noviembre de 1997, Parfums Christian Dior, asunto C-337/95, EU:C:1997:517, apdo. 21. Para una visión crítica de esta decisión véase Cienfuegos Mateo (2014: 34-36).

56 Sentencia del Tribunal de Justicia de 14 de junio de 2011, Miles y otros, asunto C-196/09, EU:C:2011:388, apdo. 41.

57 Sentencia del Tribunal de Justicia de 4 de noviembre de 1997, Parfums Christian Dior, asunto C-337/95, EU:C:1997:517, apdo. 22.

58 Sentencia del Tribunal de Justicia de 6 de marzo de 2018, Achmea, asunto C-284/16, EU:C:2018:158, apdo. 48. 
red de APPRIs intra-UE todavía en vigor ${ }^{59}$. Se estima que un mecanismo que siguiere el modelo del Tribunal Unificado de Patentes sería la mejor opción, si el objetivo perseguido consiste en proponer un tribunal que pueda dirigir cuestiones prejudiciales al TJUE ${ }^{60}$.

En cualquier caso, no parece demasiado razonable considerar a un tribunal arbitral del CIADI, aunque este venga previsto en un APPRI intra-UE, como órgano nacional cuando él mismo se identifica como Centro «Internacional $»^{61}$. Además, difícilmente se encontrarán vínculos significativos entre el arbitraje CIADI y el sistema jurisdiccional de los Estados miembros, cuando este arbitraje se distingue por sus rasgos de autonomía y exclusividad, hasta el extremo de contar con un procedimiento prácticamente autosuficiente que no precisa de la asistencia de los tribunales internos para su desarrollo y convertir la sede del arbitraje en una circunstancia prácticamente irrelevante (Fernández Masiá, 2004).

Respecto a los arbitrajes distintos al CIADI previstos en un APPRI intra-UE tampoco cabe observar vínculos equiparables a los existentes en el caso del Tribunal de Benelux, más allá de las funciones que pueden llegar a desempeñar los tribunales internos durante el desarrollo del arbitraje, en la fase de anulación o en la del reconocimiento y ejecución del laudo. A fortiori, ¿resulta lícito pretender considerar órgano jurisdiccional común a los Estados parte en el APPRI a un tribunal arbitral que puede establecer su sede en un tercer Estado (incluso no miembro de la UE) y cuyos laudos serán tratados como «extranjeros» a la hora de reconocerlos y ejecutarlos? Parece difícil dar por buena la paradoja de órganos jurisdiccionales nacionales que dictan decisiones extranjeras.

59 No obstante, resulta más que pertinente preguntarse sobre la necesidad de un mecanismo de este tipo para disputas intraeuropeas. En este sentido, Kokott y Sobotta (2016: 10); Dutheil de la Rochère (2011: 44).

60 El acuerdo sobre el Tribunal Unificado de Patentes (DO C 175, de 20 de junio de 2013, p.1). Sin embargo, en el documento presentado en el Comité de Política Comercial (Servicios e Inversión), bajo el título de «Intra-EU investment treaties. Non-paper from Austria, Finland, France, Germany and the Netherlands», disponible en https://goo.gl/waEpMR, puntos 12-14, si bien se reconoce que esta es la mejor solución desde el punto de vista técnico, razones de urgencia y coste conducen a apostar por la opción de un arbitraje ante la Corte Permanente de Arbitraje que incorpore las características del Sistema de Tribunales de Inversión que hoy impulsa la Unión en sus negociaciones con terceros Estados.

61 Sin embargo, hay quien defiende la necesidad de permitir la presentación de cuestiones prejudiciales a los tribunales y los Comités de anulación ad hoc del CIADI. En este sentido, véase Paschalidis (2016: 59-66). 
A pesar del sentido favorable de las conclusiones del abogado general M. Wathelet ${ }^{62}$, el TJUE ha venido a confirmar la posición defendida, tanto por la Comisión ${ }^{63}$ como por los propios tribunales arbitrales intra-UE ${ }^{64}$, al rechazar cualquier opción de considerarlos órganos jurisdiccionales de uno o varios Estados miembros. Para el TJUE, el tribunal arbitral de Achmea «no constituye un elemento del sistema judicial establecido en los Países Bajos y en Eslovaquia»" ${ }^{65}$. De hecho, en su opinión, una de las principales razones de ser de la disposición relativa al arreglo de diferencias inversor-Estado incorporada al APPRI es «el carácter excepcional de la jurisdicción» del

62 Conclusiones del abogado general M. Wathelet, 19 de septiembre de 2017, Achmea, asunto C284/16, EU:C:2017:699, puntos 84-131.

63 En relación con los tribunales arbitrales creados en el marco del Tratado de la Carta de la Energía, la Comisión sostiene que estos no cumplen los requisitos de permanencia, naturaleza estatal y jurisdicción obligatoria. Véase Comunicación de la Comisión Europea, C(2017) 7384 final, de 10 de noviembre de 2017, Ayuda de Estado SA.40348 (2015/NN), párr. 162. Por su parte, en el escrito de amicus curiae de la Comisión Europea en European American Investment Bank AG (EURAM) c. Eslovaquia (13 octubre 2011) SJ.i.dir (2011) 1154556, p. 5, afirmaba de forma categórica que el tribunal arbitral «is not 'court or tribunal' of an EU Member State but parallel dispute settlement mechanism entirely outside the institutional and judicial framework of the European Union».

64 En este sentido, uno de los primeros tribunales arbitrales que tuvo que entrar a valorar argumentos de derecho de la Unión, en el asunto Eastern Sugar c República Checa, laudo parcial, de 27 de marzo de 2007, Instituto de Arbitraje de la Cámara de Comercio de Estocolmo, caso núm. 088/2004, párrs. 130-131, rechazó la posibilidad de recurrir al procedimiento de remisión prejudicial incluso cuando el tribunal arbitral tuviera su sede en la UE. El tribunal arbitral de Achmea (antes Eureko) afirmó que su jurisdicción o autoridad no derivaba de la legislación de la UE como tal, sino del consentimiento de las partes en la controversia, de conformidad con el APPRI y la legislación alemana (Eureko B.V. c. República de Eslovaquia, Corte Permanente de Arbitraje, caso núm. 2008-13 [hoy, Achmea], decisión sobre jurisdicción, de 26 de octubre de 2010, párr. 225). El tribunal del caso Electrabel c. Hungría, caso CIADI núm. $\mathrm{ARB} / 07 / 19$, decisión sobre jurisdicción, de 30 de noviembre de 2012, párrs. 4.111 y 4.112., por su parte, apuntaba la naturaleza internacional del arbitraje como punto de partida necesario para su análisis. En la misma línea, el tribunal de Eiser c. España, caso CIADI núm. ARB/13/36, laudo, de 4 de mayo de 2017, párr. 199, ha recordado que su jurisdicción se deriva del Tratado de la Carta de la Energía, afirmando que «el Tribunal no es una institución del ordenamiento jurídico europeo y no está sujeto a los requisitos de dicho ordenamiento jurídico».

65 Sentencia del Tribunal de Justicia de 6 de marzo de 2018, Achmea, asunto C-284/16, EU:C:2018:158, apdo. 45. 
tribunal arbitral, en relación con la jurisdicción de los órganos judiciales de los Estados parte ${ }^{66}$.

En definitiva, considerar los tribunales de inversión como órganos jurisdiccionales de un Estado miembro (o como órganos comunes a varios Estados miembros) es forzar demasiado las costuras del art. 267 TFUE, teniendo en cuenta, además, que tal solución no supone la panacea, ya que implica abandonar la concepción comúnmente compartida en torno a estos mecanismos, caracterizada por su carácter voluntario y su naturaleza internacional o transnacional, en la medida en que la creación de los tribunales de inversión responde en gran medida a preocupaciones relacionadas con la neutralidad del juzgador $y$, por tanto, a inquietudes que solo pueden ser atendidas plenamente mediante el recurso a tribunales externos a los Estados implicados en la diferencia.

\section{TRIBUNALES DE INVERSIÓN COMO TRIBUNALES EXTERNOS AL SISTEMA JURISDICCIONAL DE LA UNIÓN EUROPEA}

La no inclusión de los mecanismos ISDS dentro del sistema jurisdiccional establecido en los tratados implica activar, en toda su amplitud, el debate en torno a la compatibilidad de los tribunales de inversión con el ordenamiento jurídico de la Unión, especialmente en relación con los elementos esenciales que sirven al objetivo de preservar la autonomía de la Unión y de su derecho y, concretamente, de asegurar la aplicación e interpretación uniformes del derecho de la Unión.

\subsection{Los mecanismos ISDS y el artículo 344 TFUE}

El art. 344 TFUE dispone que «los Estados miembros se comprometen a no someter las controversias relativas a la interpretación o aplicación de los Tratados a un procedimiento de solución distinto de los previstos en los mismos». Esta disposición está dirigida a preservar la competencia exclusiva del TJUE para la interpretación y aplicación del derecho de la $\mathrm{UE}^{67}$ y responde,

66 Ibid.

67 El caracter exclusivo de la competencia del TJUE prevista en el art. 344 TFUE ha sido señalada por el propio Tribunal en la Sentencia del Tribunal de Justicia de 30 de mayo de 2006, Comisión/Irlanda, asunto C-459/03, EU:C:2006:345, apdo. 123, y en el Dictamen 2/13 del Tribunal de Justicia de 18 de diciembre de 2014, EU:C:2014:2454, apdo. 201. 
por tanto, a la preocupación de asegurar la unidad del ordenamiento jurídico de la Unión y, en última instancia, su autonomía (Lock, 2015: 77).

$\mathrm{El}$ art. $344 \mathrm{TFUE}$, que constituye una manifestación específica del deber de cooperación leal previsto, hoy, en el art. $4.3 \mathrm{TUE}^{68}$, obliga a tomar en consideración tres aspectos (Vatsov, 2014: 870): primero, la obligación recae sobre los Estados; segundo, las controversias deben versar sobre la aplicación e interpretación del derecho de la Unión; y tercero, la controversia debe ser sometida a un procedimiento de solución distinto de los previstos en los tratados.

Cuando se entra a valorar la relación entre esta disposición y los tribunales de inversión, teniendo en cuenta el sentido de los pronunciamientos del TJUE en el asunto Mox Plant y en los dictámenes $1 / 09$ y 2/13, no resulta fácil esquivar la tentación de descartar de plano la aplicación del art. 344 TFUE a los litigios de inversión, bajo el argumento de que no son diferencias entre Estados miembros, y por el hecho de que una de las partes (que es además quien somete la diferencia a arbitraje) es un particular (López Rodríguez, 2017: 47; Schill, 2013: 44; Strik, 2010: 446; Wehland, 2009: 318-319; Zelazna, 2017: 107-108). Es así como lo han entendido, por otra parte, los distintos tribunales arbitrales en los litigios de inversión intra-UE ${ }^{69}$, hasta el punto de llegar a afirmar que: "Literalmente, dicha norma se refiere a acuerdos relativos a controversias entre los Estados Miembros, y no entre una parte privada y un Estado Miembro» ${ }^{70}$.

Efectivamente, en el asunto Mox Plant el Tribunal de Justicia consideró que el art. 344 TFUE era aplicable a las disputas entre dos Estados miembros

68 Sentencia del Tribunal de Justicia de 30 de mayo de 2006, Comisión/Irlanda, asunto C-459/03, EU:C:2006:345, apdo. 169; Dictamen 2/13 del Tribunal de Justicia de 18 de diciembre de 2014, EU:C:2014:2454, apdo. 202.

69 Véanse, de forma particular, Eureko B.V.c. República de Eslovaquia, Corte Permanente de Arbitraje, caso núm. 2008-13 (hoy, Achmea), decisión sobre jurisdicción, de 26 de octubre de 2010, párr. 276; Electrabel c. Hungría, caso CIADI núm. ARB/07/19, decisión sobre jurisdicción, de 30 de noviembre de 2012, párr. 4.151; American Investment Bank AG (EURAM) c. República de Eslovaquia, Corte Permanente de Arbitraje, caso núm. 2010-17, párrs. 254-257; y Charanne c. España, de 21 de enero de 2016, Instituto de Arbitraje de la Cámara de Comercio de Estocolmo, caso núm. V 062/2012, párrs. 441-445. También tribunales internos se han manifestado en este mismo sentido: Oberlandesgericht (Frankfurt), decisión de 10 de mayo de 2012 (26 SchH11/10), BeckRS 2012, 10291, véase Von Papp (2013, apdo. 5.1); Gáspár-Szilágyi (2016: 724).

70 Charanne c. España, de 21 de enero de 2016, Instituto de Arbitraje de la Cámara de Comercio de Estocolmo, caso núm. V 062/2012, párr. 441. 
(Irlanda y Reino Unido) relativas a la interpretación y aplicación del derecho de la Unión (apartados de la Convemar de la competencia de la UE) ${ }^{71}$. El Dictamen $1 / 09$, por su parte, descartó la aplicación de esta disposición por tratarse de un mecanismo de solución de diferencias entre particulares (el Tribunal Europeo y Comunitario de Patentes [TP] $)^{72}$. Finalmente, el Dictamen 2/13 parece venir a confirmar la exclusión de las diferencias que afectan a particulares del ámbito de aplicación del art. 344 TFUE, al centrar su análisis en las controversias del art. 33 del CEDH, es decir, las interestatales, dejando al margen cualquier valoración sobre las demandas individuales del art. 34 $\mathrm{CEDH}$, dando a entender, de esta forma, que estas no se encuentran cubiertas por el art. $344 \mathrm{TFUE}^{73}$.

No obstante, varias consideraciones pueden conducir a no descartar de plano la inclusión de las disputas entre inversores y Estados en el ámbito del art. 344 TFUE (Von Papp, 2013: apdo. 6.1.). En este sentido, el hecho de que el TJUE en el asunto Mox Plant haya afirmado que las disputas entre Estados miembros, como la que centra su debate, se encuentran incluidas en el art. 344 TFUE no implica necesariamente excluir otro tipo de disputas en las que también esté implicada la decisión de un Estado miembro de sustraer controversias de los procedimientos previstos en los tratados. De hecho, el Tribunal de Justicia en su Dictamen 2/13 ha reconocido que las disputas afectadas por el art. 344 TFUE pueden ser tanto las que surgen entre los Estados miembros como las que se dan entre un Estado miembro y la $\mathrm{UE}^{74}$. Los argumentos que explican la irrelevancia del art. 344 TFUE en relación con el TP no son necesariamente válidos para las controversias de inversión, en la medida en que en este último caso un Estado miembro es parte en la diferencia y juega un papel determinante en la decisión de someter esa controversia a un tribunal de inversión. Asimismo, existen argumentos de peso que explican por qué el Dictamen 2/13 se ha limitado a las controversias interestatales, dejando las

71 Sentencia del Tribunal de Justicia de 30 de mayo de 2006, Comisión/Irlanda, asunto C-459/03, EU:C:2006:345, apdos. 128 y 132. Convención de las Naciones Unidas sobre el Derecho del Mar, de 16 de noviembre de 1994 (U.N.T.S. vol. 1834, p. 371).

72 Dictamen 1/09 del Tribunal de Justicia de 8 de marzo de 2011, EU:C:2011:123, apdo. 63.

73 Dictamen 2/13 del Tribunal de Justicia de 18 de diciembre de 2014, EU:C:2014:2454, apdos. 201-214. Esta es la argumentación que hacen suya, por ejemplo, las conclusiones del abogado general M. Wathelet, de 19 de septiembre de 2017, Achmea, asunto C284/16, EU:C:2017:699, apdos. 151-152, para justificar la exclusión del arbitraje de inversiones del alcance del art. 344 TFUE.

74 Dictamen 2/13 del Tribunal de Justicia de 18 de diciembre de 2014, EU:C:2014:2454, apdo. 204. Véase Lock (2015: 84). 
demandas individuales contra Estados miembros fuera del alcance del art. 344 TFUE. Ello se encuentra justificado por la siguiente circunstancia: las posibilidades de que un Estado miembro incumpla el compromiso asumido en el art. 344 TFUE se circunscriben exclusivamente al art. 33 CEDH. Cuando se trate de una demanda individual conforme al art. $34 \mathrm{CEDH}$ el Estado miembro no participa en la decisión de someter la diferencia a un procedimiento distinto a los previstos en los tratados, ya que, por una parte, solo el particular puede actuar como demandante y, por otra, el consentimiento de reconocer la jurisdicción del TEDH en los ámbitos de la competencia de la UE, mediante la hoy por hoy malograda celebración de un acuerdo de adhesión al CEDH, correspondería exclusivamente a la propia UE y no a sus Estados miembros. No obstante, no puede decirse lo mismo de los mecanismos ISDS, donde, si bien son los inversores quienes, en última instancia, deciden someter una controversia a un tribunal de inversiones, esta decisión viene precedida por la prestación del consentimiento del Estado miembro, generalmente, a través de la celebración de un tratado de inversiones. En este sentido, puede sostenerse que los Estados miembros juegan un papel necesario y fundamental en la decisión de someter una diferencia a mecanismos ISDS.

El TJUE, mediante la sentencia de Achmea, a pesar de no manifestarlo expresamente, respalda definitivamente la inclusión de las disputas inversor-Estado dentro del art. 344 TFUE, desde el momento en el que concluye que este artículo debe interpretarse en el sentido de que se opone a las disposiciones sobre arreglo de diferencias inversor-Estado incluidas en los APPRI intra-UE ${ }^{75}$.

$\mathrm{Si}$ se asume que las disputas inversor-Estado no se encuentran, per se, excluidas del art. 344 TFUE, existe un segundo aspecto, no menos importante, que debe ser considerado: que la disputa se refiera a la interpretación o aplicación de los tratados, es decir, del derecho de la Unión (Dimopoulos, 2011: 85-87). Al respecto, los APPRI intra-UE no son derecho de la Unión, en la medida que son producto del ejercicio de las competencias de los Estados miembros. Por tanto, una controversia relativa a la violación del tratado difícilmente cumplirá esta segunda condición que impone el art. 344 TFUE. La conclusión podría ser distinta si el tribunal de inversiones no se limitara a resolver posibles infracciones del tratado, sino que, además, se ocupara de dirimir violaciones de otros cuerpos normativos, señaladamente del derecho de la Unión. Sin embargo, este no es un supuesto habitual. Por otra parte, el hecho de que un tribunal de inversiones, como parte del derecho aplicable a la

75 Sentencia del Tribunal de Justicia de 6 de marzo de 2018, Achmea, asunto C-284/16, EU:C:2018:158, apdo. 60 . 
controversia, deba tomar en consideración normas del ordenamiento jurídico de la Unión para determinar la posible violación de un APPRI intra-UE no debería convertir dicha controversia en un litigio relativo a la interpretación y aplicación de los tratados, menos aún teniendo en cuenta que no existe una identidad material en los contenidos de las previsiones de los APPRI y las del ordenamiento jurídico de la Unión ${ }^{76}$.

No obstante, el TJUE no comparte esta última afirmación, tal y como ha quedado claramente reflejado en su sentencia Achmea. Así, el TJUE ha señalado que cuando el tribunal arbitral se vea obligado a "tener en cuenta», como parte del derecho aplicable, el derecho de la UE, incluso a los efectos de determinar la infracción del propio APPRI, esa controversia debe ser considerada relacionada con la interpretación o aplicación del ordenamiento jurídico de la UE ${ }^{77}$. Esta constatación constituye la principal razón por la cual el TJUE ha considerado al arbitraje de inversiones intra-UE incompatible con el derecho de la UE. Se trata, además, de un argumento que, si bien el TJUE guarda silencio, podría extenderse al arbitraje de inversiones de los APPRI extra-UE, en cuanto no parece que pueda descartarse que en algunas de las controversias iniciadas bajo estos APPRI el derecho de la UE forme parte del derecho aplicable, especialmente, cuando el demandado sea un Estado miembro de la UE.

En cuanto a los APPRI extra-UE, tampoco deberían ser considerados como parte del derecho de la Unión. A pesar de que hoy, tras el Tratado de Lisboa y las precisiones hechas por el TJUE en el Dictamen 2/15, el ejercicio de la competencia sobre gran parte de los ámbitos cubiertos por estos tratados corresponda a la Unión, no resulta razonable sostener que los mismos se encuentren integrados en el ordenamiento jurídico de la Unión, debido a que no pueden considerase vinculantes para la UE, en atención a los criterios establecidos por la jurisprudencia del propio Tribunal ${ }^{78}$.

Para finalizar, resulta obligado hacer una breve referencia a los futuros TLCI de la UE en el marco del art. 344 TFUE. En la medida en que estos

76 En este mismo sentido, conclusiones del abogado general M. Wathelet, de 19 de septiembre de 2017, Achmea, asunto C284/16, EU:C:2017:699, apdo. 173.

77 Sentencia del Tribunal de Justicia de 6 de marzo de 2018, Achmea, asunto C-284/16, EU:C:2018:158, apdos. 39-42.

78 Sobre esta cuestión: Sentencia del Tribunal de Justicia de 12 de diciembre de 1972, International Fruit Company, asunto C-21/72, EU:C:1972:115, apdos. 15-18; Sentencia del Tribunal de Justicia de 3 de junio de 2008, Intertanko y otros, asunto C-308/06, EU:C:2008:312, apdo. 48, Sentencia del Tribunal de Justicia de 22 de octubre de 2009, Bogiatzi, asunto C-301/08, EU:C:2009:649, apdos. 25-34; Sentencia del Tribunal de Justicia de 21 de diciembre de 2011, Air Transport Association of America y otros, asunto C-366/10, EU:C:2011:864, apdos. 62-63. 
TLCI son tratados de la Unión se integran en el ordenamiento jurídico de la Unión y vinculan tanto a sus instituciones como a los Estados miembros ${ }^{79}$. Sin embargo, dejando al margen las reflexiones que surgen a raíz de la naturaleza mixta de estos tratados, el hecho de que sea la propia Unión quien decide someter la interpretación y aplicación del tratado a mecanismos ISDS externos al sistema jurisdiccional de la Unión hace imposible que este supuesto se incluya en el art. 344 TFUE, que solo impone obligaciones a los Estados miembros (Burgstaller, 2012: 217; Schill, 2013: 44). Tampoco parece razonable plantear como hipótesis en el marco de estos tratados controversias intra-UE iniciadas por voluntad de los Estados miembros, tal y como, por otra parte, sucedía en los supuestos del asunto Mox Plant y del Dictamen $2 / 13$, en la medida en que sus disposiciones sustantivas para la protección de las inversiones no son susceptibles de aplicación en las relaciones intraeuropeas y sus mecanismos ISDS están previstos exclusivamente para supuestos internacionales ${ }^{80}$.

\subsection{Tribunales de inversión y la salvaguardia de las características específicas de la Unión y de su derecho}

Los tratados celebrados por la UE forman parte integrante del derecho de la Unión y corresponde al TJUE pronunciarse en caso de incumplimiento por parte de los Estados miembros, así como con carácter prejudicial cuando se requiera una interpretación autorizada. Sin embargo, según jurisprudencia asentada del TJUE, ello no obsta para que la Unión, en un acuerdo internacional, prevea la creación de un órgano jurisdiccional encargado de la interpretación y aplicación de las disposiciones del propio acuerdo, cuyas decisiones sean vinculantes para las instituciones de la Unión. Tal facultad constituye una atribución necesaria de la competencia de la UE en materia de relaciones internacionales y su capacidad para celebrar acuerdos internacionales ${ }^{81}$. Por su parte, respecto al arbitraje comercial, como método de solución de controversias ajeno al sistema jurisdiccional previsto en los tratados, el derecho de la Unión ha mantenido una posición de tolerancia, gracias a que las decisiones

79 Art. 216.2 TFUE. Sentencia del Tribunal de Justicia de 30 de abril de 1974, Haegeman, asunto 181/73, EU:C:1974:41, apdo. 5.

80 Esta idea se desprende, por ejemplo, del art. 30.6 del CETA (DO L 11, de 14 de enero de 2017, p. 23). Véase Schill (2015: 385).

81 Dictamen 1/91 del Tribunal de Justicia de 14 de diciembre de 1991, EU:C:1991:490, apdos. 40 y 70; Dictamen 1/09 del Tribunal de Justicia de 8 de marzo de 2011, EU:C:2011:123, apdo. 74; Dictamen 2/13 del Tribunal de Justicia de 18 de diciembre de 2014, EU:C:2014:2454, apdo. 182. 
de estos tribunales arbitrales se prestan a una revisión en los tribunales internos en las distintas fases del procedimiento arbitral y posterior ejecución del laudo $^{82}$. Dicho esto, en principio, los mecanismos de ISDS previstos en los tratados de inversión que resuelven controversias relativas a infracciones del propio tratado y aquellas decisiones arbitrales que sean susceptibles de revisión ante los órganos jurisdiccionales de los Estados miembros no deberían plantear problemas de compatibilidad con el derecho de la Unión.

El hecho de que el sometimiento a un mecanismo de arreglo de diferencias externo al sistema jurisdiccional previsto en los tratados pueda no ser considerado contrario al art. 344 TFUE no significa que este, necesariamente, sea compatible con el derecho de la Unión. Muy al contrario, el propio TJUE se ha encargado de definir las condiciones que debe respetar todo tribunal externo de modo que quede salvaguardada la autonomía del ordenamiento jurídico de la Unión, a través de una jurisprudencia que se ha caracterizado por mostrar una actitud muy protectora de sus funciones y, por tanto, extremadamente exigente en cuanto a los requisitos que deben satisfacer.

Tras el análisis de las principales decisiones del TJUE que han desarrollado la noción de la autonomía, cabe señalar, sumariamente, que los tribunales externos deben respetar los siguientes límites para que sean considerados compatibles con el ordenamiento jurídico de la Unión: 1) no se debe socavar la competencia del TJUE para resolver cualquier cuestión relativa al orden de competencias definido en los tratados ${ }^{83}$, lo que incluye la distribución de competencias entre la Unión y los Estados miembros y las competencias de las propias instituciones ${ }^{84}$; 2) los tribunales externos no pueden imponer al TJUE interpretaciones vinculantes del derecho de la Unión ${ }^{85}$; 3) solo le corresponde al TJUE pronunciarse sobre la legalidad de los actos de la $\mathrm{UE}^{86}$; 4) los Estados miembros no

82 Sentencia del Tribunal de Justicia de 23 de marzo de 1982, Nordsee, C-102/81, EU:C:1982:107.

83 Dictamen 1/91 del Tribunal de Justicia de 14 de diciembre de 1991, EU:C:1991:490, apdos. 33-36.

84 Tal y como indica el Dictamen 1/00 del Tribunal de Justicia de 18 de abril de 2002, EU:C:2002:231, apdo. 21, el acuerdo puede afectar a las competencias de las instituciones de la Unión pero no desvirtuarlas.

85 Dictamen 1/91 del Tribunal de Justicia de 14 de diciembre de 1991, EU:C:1991:490, apdos. 41-46; Dictamen 1/00 del Tribunal de Justicia de 18 de abril de 2002, EU:C:2002:231, apdo. 13; Dictamen 2/13 del Tribunal de Justicia de 18 de diciembre de 2014, EU:C:2014:2454, apdo. 184.

86 El Dictamen 1/00 del Tribunal de Justicia de 18 de abril de 2002, EU:C:2002:231, apdo. 24, se refiere al «monopolio del control de legalidad de los actos de las instituciones comunitarias». 
pueden extraer las diferencias relativas a la interpretación y aplicación del derecho de la UE de los procedimientos de solución previstos en los tratados (art. 344 TFUE $)^{87}$; y 5) no se pueden sustraer las disputas de la competencia de los tribunales internos de los Estados miembros, si ello supone poner en riesgo la unidad y la aplicación e interpretación uniformes del derecho de la Unión ${ }^{88}$. En definitiva, empleando la expresión del TJUE en el Dictamen 2/13, la autonomía exige preservar «las características específicas de la Unión y de su derecho».

El TJUE, en el Dictamen 1/91, al referirse a la competencia del Tribunal del Espacio Económico Europeo (Tribunal EEE), observó que esta alcanzaba a las controversias entre las partes contratantes. No obstante, tratándose de un acuerdo mixto, la identificación, en cada litigio, como parte contratante a la Comunidad o a los Estados miembros dependía del alcance de las respectivas competencias. Por tanto, que el Tribunal EEE pudiera interpretar el concepto de parte contratante implicaba entrar a decidir sobre el reparto competencial establecido en los tratados comunitarios. Ello, en opinión del Tribunal de Justicia, supondría: «vulnerar el orden de competencias definido en los Tratados y, por lo tanto, la autonomía del sistema jurídico comunitario» ${ }^{89}$. Pues bien, de lo dicho se desprende que los arbitrajes de inversión previstos en los APPRI, no siendo acuerdos mixtos, ni siquiera llegan a plantear este problema $^{90}$.

Bien al contrario, los nuevos TLCI de la UE, en la medida en que se refieran tanto a las inversiones extranjeras directas como a las indirectas e incluyan mecanismos ISDS que sustraigan controversias de la competencia de los tribunales internos de los Estados miembros ${ }^{91}$, serán tratados de naturaleza mixta y, en consecuencia, en caso de controversia será necesario determinar quién responderá como demandado (la UE o algún Estado miembro) ante los procedimientos iniciados por inversores de la otra parte contratante ${ }^{92}$.

87 Véase supra, epígrafe 3.1.

88 Dictamen 1/09 del Tribunal de Justicia de 8 de marzo de 2011, EU:C:2011:123, apdos. 83-87.

89 Dictamen 1/91 del Tribunal de Justicia de 14 de diciembre de 1991, EU:C:1991:490, apdos. 33-36 (en especial, el apdo. 35).

90 Dictamen 1/00 del Tribunal de Justicia de 18 de abril de 2002, EU:C:2002:231, apdos. 15-17.

91 Dictamen 2/15 del Tribunal de Justicia de 16 de mayo de 2017, EU:C:2017:376.

92 En el marco de otros tratados mixtos se ha tratado de resolver este problema a través de distintas técnicas. Así, en el contexto del Tratado de la Carta de la Energía, las Comunidades Europeas comunicaron una declaración según la cual «las Comunidades y los Estados miembros afectados determinarán, si es necesario, quién de ellos es la parte demandada en los procedimientos de arbitraje incoados por un inversor de 
Sabedores de los límites que impone, en este sentido, la autonomía del derecho de la Unión, la UE y los Estados miembros tratan de dar una solución al problema mediante la introducción en los textos de los nuevos tratados de una disposición que deja en manos de la propia UE dicha determinación; y en los casos en los que la UE no proceda a dicha determinación el inversor podrá presentar una demanda atendiendo a la autoría de la medida o trato sobre el que gire la reclamación ${ }^{93}$. Es importante destacar que, en realidad, en el marco de estas disposiciones no existe un pronunciamiento sobre la distribución de competencias entre la Unión y los Estados miembros. La determinación del demandado, bien cuando sea obra de la UE, que podrá decidir de conformidad con lo dispuesto en el Reglamento 912/201494, bien cuando sea el propio inversor quien lo haga en el momento de la presentación de la demanda, no se fundamenta en la titularidad del ejercicio de la competencia, sino en la autoría del trato sometido a juicio del tribunal de inversiones ${ }^{95}$; esta circunstancia podría ser suficiente para superar el elevado umbral establecido por el TJUE en relación con la figura del codemandado en el Dictamen $2 / 13^{96}$.

otra Parte contratante. En este caso, a instancia del inversor, las Comunidades y los Estados miembros afectados tomarán esa determinación dentro de un plazo de treinta días» (DO L 69, de 9 de marzo de 1998, p. 115). Schill (2013: 49-50) considera que un procedimiento así protegería la autonomía del derecho de la Unión. En la misma línea, Dimopoulos (2014: 1700-1702). Por su parte, en el caso de la Convemar, su Anexo IX ha optado por definir ex ante, en declaraciones contenidas en los instrumentos de confirmación formal o de adhesión, o en el momento de su ratificación, las materias que son competencia de la Unión y las que son de competencia de los Estados miembros.

93 Art. 8.21 CETA; art. 9.15 del TLCI de la UE y Singapur; art. 6 del capítulo 8, capítulo II, sección 3, subsección 1 TLCI de la UE y Vietnam. Para una visión crítica de estas disposiciones, véase López Rodríguez (2017: 48).

94 Reglamento (UE) 912/2014 del Parlamento Europeo y del Consejo, de 23 de julio de 2014, por el que se establece un marco para gestionar la responsabilidad financiera relacionada con los tribunales de resolución de litigios entre inversores y Estados establecidos por acuerdos internacionales en los que la Unión Europea sea parte (DO L 257, de 28 de agosto de 2014, p. 121). Veánse Fernández Rozas (2014: 5-27); Iruretagoiena Agirrezabalaga (2015: 335-338); Kleinheisterkamp (2014: 449-476); Pascual Vives (2015: 294-298).

95 El propio Reglamento (UE) 912/2014 en su art. 1 comienza señalando que el reglamento se aplica «sin perjuicio del reparto de competencias establecido en el TFUE».

96 El TJUE en el Dictamen 2/13 del Tribunal de Justicia de 18 de diciembre de 2014, EU:C:2014:2454, apdos. 215-235. Véanse González Vega (2015: 1-43); Halberstam (2015: 115-118). 
Son mayores las incógnitas que suscita la actividad de los tribunales de inversión en relación con los efectos que esta puede generar en la interpretación y aplicación uniforme del derecho de la Unión. Al respecto, el Dictamen 1/91 del TJUE introdujo el principio según el cual un órgano jurisdiccional externo a la UE no puede imponer al TJUE una interpretación vinculante de las normas del ordenamiento jurídico de la Unión; así, condicionar la interpretación futura de estas normas debe considerarse contrario a los fundamentos de la Unión ${ }^{97}$. Sin embargo, el caso del Tribunal EEE que trata el Dictamen 1/91 no resulta equiparable al de los tribunales de inversión, dado que las disposiciones sustantivas de los tratados de inversión que estos tribunales interpretan y aplican no se yuxtaponen a normas del ordenamiento jurídico de la Unión y, por tanto, no presentan un contenido idéntico a aquellas, ni persiguen una finalidad armonizadora entre el régimen previsto en los tratados de inversión y el derecho de la Unión (Govaere, 2010: 197; Zelazna, 2017: 97). En consecuencia, no hay motivos para pensar que la interpretación y la aplicación de las previsiones de los tratados de inversión puedan llegar a condicionar la interpretación futura de las normas del derecho de la Unión.

Por su parte, al contrario de lo que sucedía en el caso del TP, cuya competencia alcanzaba, más allá de la interpretación del propio acuerdo, a controversias intraeuropeas regidas por el derecho de la Unión ${ }^{98}$, los tribunales de inversión, generalmente, resuelven diferencias relativas a infracciones de los tratados de inversión. En este sentido, los nuevos TLCI de la UE, por ejemplo, limitan expresamente la competencia de los tribunales de inversión a las reclamaciones convencionales ${ }^{99}$.

No obstante, el hecho de limitar la jurisdicción de los tribunales de inversión a los treaty claims no excluye que, en ciertas ocasiones, estos deban o puedan entrar a considerar, como paso preliminar, cuestiones de derecho de la Unión, bien como parte del derecho aplicable, bien como una cuestión de hecho, en el marco de un procedimiento dirigido, en la mayoría de los casos, a determinar la violación del propio tratado de inversiones (Strik, 2010: 434441). La presencia y, en su caso, interpretación de normas del ordenamiento jurídico de la Unión en los litigios de inversión provoca preocupación, en la medida en que podría perjudicar la uniformidad en la interpretación y la aplicación de sus normas e, incluso, podría conducir a cuestionar la legalidad

97 Dictamen 1/91 del Tribunal de Justicia de 14 de diciembre de 1991, EU:C:1991:490, apdo. 46.

98 Ibid., apdo. 78.

99 Véase, por ejemplo, el art. 8.18 CETA; art. 9.11 del TLCI de la UE y Singapur; art. 1 del capítulo 8, capítulo II, sección 3, subsección 1 TLCI de la UE y Vietnam. 
misma de los actos de las instituciones de la Unión. Precisamente, tal y como se ha visto en el epígrafe anterior, ha sido este - junto al hecho de que son los propios Estados miembros quienes sustraen los litigios de la competencia de los tribunales internos- el principal argumento que ha conducido al TJUE a declarar la incompatibilidad del arbitraje de inversiones previsto en los APPRI intra-UE.

Una vez señaladas estas cuestiones, resultan pertinentes varias precisiones. En primer lugar, es inherente a la facultad de los tribunales de inversión valorar la licitud de los actos y medidas de la Unión y de sus Estados miembros conforme a los estándares previstos en los respectivos tratados de inversión. Por tanto, entra dentro de la normalidad la posibilidad de que un comportamiento lícito conforme al derecho de la Unión sea considerado ilícito conforme al tratado de inversiones ${ }^{100}$. En este sentido, el tribunal de inversiones no tiene por qué entrar a cuestionar la legalidad de los actos de la Unión conforme al derecho de la Unión para determinar la violación del tratado de inversiones derivada de tales actos (Dimopoulos, 2014: 1699) ${ }^{101}$.

En segundo lugar, que un tribunal de inversiones, como cuestión preliminar, realice una interpretación concreta del derecho de la UE no tiene por qué "condicionar la interpretación futura» de esa norma por parte del TJUE, menos aún cuando los laudos no constituyen precedentes obligatorios ni para los tribunales arbitrales creados con posterioridad en el marco de una misma institución arbitral o cuando estos son confidenciales. En este sentido, pretender imponer una noción de autonomía que no deje espacio alguno para la aplicación incidental (o instrumental) de normas del ordenamiento jurídico de la Unión en tribunales ajenos al sistema jurisdiccional diseñado en los tratados, supone adoptar una posición excesivamente proteccionista que puede conducir al «aislacionismo» del propio ordenamiento ${ }^{102}$.

100 En propio el Reglamento (UE) 912/2014 del Parlamento Europeo y del Consejo, de 23 de julio de 2014, prevé con naturalidad la posibilidad de que existan comportamientos que siendo exigidos por el derecho de la Unión sean considerados contrarios a los compromisos asumidos en los TLCI adoptados por la Unión y sus Estados miembros. Tal y como pone de manifiesto Govaere (2010: 194-196), si la prohibición de cuestionar la legalidad de los actos de la Unión significara que estos no pueden ser cuestionados por la violación de acuerdos internacionales en los mecanismos de arreglo de diferencias internacionales previstos, no tendría mucho sentido permitir que la UE establezca tales mecanismos.

101 En este sentido, véase el art. 8.31.2 del CETA.

102 Término empleado por Martín y Pérez de Nanclares (2015: 836), en relación con el Dictamen 2/13. Desafortunadamente, esta parece ser la opción preferida por el TJUE, puesta de manifiesto en la sentencia Achmea, donde ya no se habla de no 
En cualquier caso, los nuevos TLCI de la UE vienen incorporando previsiones específicas dirigidas a desactivar $\mathrm{o}$, al menos, atenuar las reticencias que algunos todavía pueden albergar sobre la cuestión debatida. Así, la previsión relativa al «derecho aplicable e interpretación» del CETA, por ejemplo, dispone que, para determinar la conformidad de una medida con el propio acuerdo, el tribunal "podrá tener en cuenta [...] el Derecho interno de una Parte como un elemento de hecho", dándole, de este modo, a las normas de la Unión la consideración de derecho interno. Además, se establece que el tribunal deberá seguir la interpretación predominante dada por los órganos jurisdiccionales o las autoridades correspondientes, e insiste en que la interpretación que pueda realizar el tribunal no será vinculante para esos órganos jurisdiccionales o esas autoridades ${ }^{103}$.

En tercer lugar, en todo caso, los tribunales de inversión podrían pronunciarse sobre cuestiones de derecho de la Unión, siempre y cuando existieran mecanismos o fórmulas para preservar, en el marco de sus respectivos procedimientos, la competencia del TJUE para realizar la interpretación última y autorizada de las normas del ordenamiento jurídico de la Unión. Así, una primera fórmula podría consistir en la previsión de un mecanismo a través del cual los tribunales de inversión pudieran remitir directamente al TJUE cuestiones relativas a la interpretación de normas del derecho de la Unión. No obstante, en los tratados de inversión no existen, ni están previstos en los futuros TLCI de la UE, este tipo de cauces de intervención directa previa del TJUE (Von Papp: 2013). Además, el Dictamen 1/09 del Tribunal de Justicia dibujó un escenario francamente difícil para la viabilidad de cualquier mecanismo de esta índole que pretenda al mismo tiempo privar a los órganos jurisdiccionales de los Estados miembros de su facultad de plantear cuestiones prejudiciales conforme al art. 267 TFUE $^{104}$.

"condicionar la interpretación futura» de las normas de la UE, sino de «garantizar la plena eficacia» del derecho de la UE. Sentencia del Tribunal de Justicia de 6 de marzo de 2018, Achmea, asunto C-284/16, EU:C:2018:158, apdos. 36 y 56. No obstante, se podría interpretar que esta apreciación afecta exclusivamente a la obligación del art. 344 TFUE y no, de forma general, a cualquier tribunal externo que se pueda crear mediante tratado la UE.

103 Art. 8.31 CETA; en la misma línea, art. 16 del capítulo 8, capítulo II, sección 3, subsección 5 TLCI de la UE y Vietnam. Ankersmit (2016: 53) considera que es cuestionable si esta formulación será suficiente para evitar que los tribunales ISDS se refieran a cuestiones de derecho de la Unión.

${ }^{104}$ El acuerdo preveía que la Sala de Primera Instancia del TP podría dirigir peticiones prejudiciales y, en cambio, la Sala de Apelación tenía la obligación de plantear dichas cuestiones cuando fuera necesario establecer la interpretación de una norma del de- 
Una segunda alternativa consistiría en diseñar mecanismos ISDS que permitieran remisiones indirectas al TJUE, de tal manera que estuviera garantizada la revisión o el control de la aplicación e interpretación de las normas del ordenamiento jurídico de la Unión realizada por los tribunales de inversión. En este sentido, la jurisprudencia del TJUE, desarrollada, entre otros, en los asuntos Nordsee ${ }^{105}$, Eco Swiss ${ }^{106}$ o Genentech ${ }^{107}$, constituye un elemento valioso para defender la compatibilidad de los mecanismos ISDS cuando, bien en algún momento durante el desarrollo del procedimiento, bien tras haberse dictado su decisión en el marco de un procedimiento de anulación ${ }^{108}$ o de reconocimiento y ejecución ${ }^{109}$, los órganos jurisdiccionales de un Estado miembro tuvieran la oportunidad de dirigir una petición prejudicial al TJUE conforme al art. 267 TFUE (Basedow, 2015: 374-376; Penadés Fons, 2016: 817-833). La existencia de esta opción permitiría al TJUE cumplir su función de intérprete supremo del ordenamiento jurídico de la Unión y, en definitiva, de salvaguardar las características específicas de la Unión y de su derecho. Además, si el órgano jurisdiccional nacional dejara de cumplir con su obligación de plantear una cuestión prejudicial cuando estuviera obligado a ello, permitiendo así una decisión contraria al derecho de la Unión, quedaría abierto el camino para reclamar la responsabilidad del Estado miembro o para iniciar contra este un procedimiento por incumplimiento sobre la base de los arts. 258 y 259 TFUE.

Sin embargo, el TJUE ha venido a echar por tierra la posibilidad de valerse de los precedentes relativos al arbitraje comercial. El hecho de que el laudo

recho de la Unión; sin embargo, ello no bastó para que este mecanismo fuera considerado compatible con el derecho de la Unión, dado que no resultaba posible iniciar un procedimiento por incumplimiento o declarar la responsabilidad patrimonial de ningún Estado miembro en caso de que el TP dictara una resolución que infringiera el derecho de la Unión; Dictamen 1/09 del Tribunal de Justicia de 8 de marzo de 2011, EU:C:2011:123, apdo. 88. Véase González Alonso (2012: 251-274).

105 Sentencia del Tribunal de Justicia de 23 de marzo de 1982, Nordsee, C-102/81, EU:C:1982:107.

106 Sentencia del Tribunal de Justicia de 1 de junio de 1999, Eco Swiss, asunto C-126/97, EU:C:1999:269.

107 Sentencia del Tribunal de Justicia de 7 de julio de 2016, Genentech, asunto C-567/14, EU:C:2016:526.

108 Este ha sido el caso en los asunto Eco Swiss y Genentech.

109 Sentencia del Tribunal de Justicia de 13 de mayo de 2015, Gazprom, asunto C-536/13, EU:C:2015:316, por su parte, la petición prejudicial se realiza en el marco de un recurso interpuesto contra la denegación del reconocimiento y ejecución en Lituania de un laudo arbitral. 
arbitral en materia de inversiones se preste únicamente a un control limitado ante los tribunales internos del Estado miembro, como es el caso en Achmea, impediría garantizar la plena eficacia del derecho de la UE. Según el TJUE el carácter limitado del control se encuentra justificado en el arbitraje comercial por «exigencias relativas a la eficacia del procedimiento arbitral» ${ }^{110}$. No obstante, en su opinión, estas apreciaciones no son extrapolables al arbitraje de inversiones, principalmente porque si bien en el arbitraje comercial su origen se encuentra en la autonomía de la voluntad de las partes, en el arbitraje de inversiones este se halla en un tratado «mediante el cual los Estados miembros se comprometen a sustraer de la competencia de sus propios tribunales [...] los litigios que puedan referirse a la aplicación o interpretación de ese Derecho» ${ }^{111}$. Para el tribunal, el art. 19.1 TUE, en estos casos, exige a los Estados miembros establecer vías de recurso judicial. En su lugar, prever un arbitraje de inversiones que no asegura la plena eficacia del derecho de la UE resulta incompatible con el principio de cooperación leal, ya que supone poner en peligro el principio de confianza mutua entre Estados miembros y el carácter propio del derecho de la UE ${ }^{112}$. Dicho lo cual, en relación con el pronunciamiento del TJUE en el asunto Achmea cabe preguntarse si las diferencias señaladas entre el arbitraje comercial y el de inversiones justifican realmente la disparidad de conclusiones alcanzadas. En este sentido, no debe olvidarse que el alcance de la autonomía de la voluntad depende de la opción normativa de cada Estado, cuando determina cuáles son las materias arbitrables. Así, si se aplicara el principio de cooperación leal hasta sus últimas consecuencias, ¿no sería exigible a los Estados miembros la exclusión de las diferencias que se refieran a la interpretación o aplicación del derecho de la UE de los supuestos que son susceptibles de ser resueltos recurriendo al arbitraje?

En cualquier caso, el recurso a esta remisión indirecta estaría lejos de constituir la solución global para la variedad de mecanismos ISDS presentes hoy en Europa. Así, en cuanto a los arbitrajes de inversión clásicos, nada se opone a que en un arbitraje iniciado sobre la base de un APPRI intra-UE la sede del arbitraje se sitúe en un tercer Estado, ni a que la ejecución de ese laudo sea pretendida fuera de la UE. ¿̇Y qué decir del arbitraje CIADI, descrito como arbitraje «anacional» por la irrelevancia del factor de la sede y donde únicamente está permitido el recurso de anulación ante los comités de

110 Sentencia del Tribunal de Justicia de 6 de marzo de 2018, Achmea, asunto C-284/16, EU:C:2018:158, apdo. 54.

111 Ibid., apdo. 55.

112 Ibid., apdo. 58. 
anulación de propio Centro? ${ }^{113}$ En estos últimos supuestos no habrá forma de garantizar la intervención del Tribunal de Justicia. Por su parte, en el Sistema de Tribunales de Inversión que incorporan tanto el CETA como el TLCI de la UE y Vietnam se limitan las opciones de intervención de los órganos jurisdiccionales nacionales. Así, ambos textos señalan que las decisiones del tribunal de apelación del Sistema de Tribunales de Inversión no serán objeto de recurso de anulación ${ }^{114}$.

\section{CONCLUSIONES}

La salvaguardia de la autonomía del ordenamiento jurídico de la UE constituye una exigencia legítima y necesaria para preservar sus características esenciales y, en definitiva, la consecución de los objetivos establecidos en los tratados de la Unión. Sin embargo, una actitud demasiado protectora puede conducir a un «diálogo de sordos» entre el TJUE y los tribunales de inversión o, peor aún, a un monólogo, lo que, sin lugar a dudas, repercutirá negativamente en la aplicación armoniosa de los distintos ordenamientos jurídicos e intereses en presencia.

El sentido y, sobre todo, el tono de la jurisprudencia previa del TJUE no llaman al optimismo. Este presentimiento se ha visto confirmado con la sentencia Achmea, que podría, incluso, llegar a tener repercusiones más allá de los arbitrajes previstos en los APPRI intra-UE. Por otra parte, aun teniendo en cuenta la aportación positiva de las previsiones que incorporan los nuevos TLCI de la Unión a fin de superar los obstáculos que impone esta noción de la autonomía, no es posible predecir con seguridad si estas serán suficientes.

Ahora que está en juego el futuro de los mecanismos ISDS en la UE, y por extensión el de las jurisdicciones externas en el marco de los acuerdos que la Unión pueda llegar a celebrar, se impone tenuemente la impresión de que, en realidad, es más una cuestión de talante y de voluntad para establecer un diálogo real entre tribunales, que una cuestión de encaje jurídico. En cualquier caso, sería deseable que se establecieran cauces, formales e informales,

$\overline{113}$ En este sentido, en sus conclusiones el abogado general en el asunto Achmea desaconseja acudir al CIADI y deja claro que la solución que propone es una solución para el caso concreto; Conclusiones del abogado general M. Wathelet, 19 de septiembre de 2017, Achmea, asunto C284/16, EU:C:2017:699, punto 253. Véase Von Papp, 2013, apdo. 7.

114 Art. 8.28.9.b) CETA; art. 10 del capítulo 8, capítulo II, sección 3, subsección 3 y art. 31 del capítulo 8, capítulo II, sección 3, subsección 5 TLCI de la UE y Vietnam. 
a través de los cuales se pudiera desarrollar ese diálogo tan necesario, y que sirvieran, a su vez, para crear un marco de relaciones de confianza, respeto mutuo y cooperación entre distintos tribunales.

En el sentido que propone este artículo - y dejando al margen el pronunciamiento del asunto Achmea dada la particularidad del arbitraje intra-UE-, en caso de que sea ahora cuando el TJUE inicie la maniobra para fijar un nuevo rumbo, más proclive al reconocimiento de jurisdicciones externas, no dejaría de ser una suerte de justicia poética que la Unión quedara retratada como la organización que no habiendo sido capaz de reaccionar ante el apasionante reto que suponía someterse al TEDH, lo haya sido en un contexto donde lo que se cuestiona es la compatibilidad de unos tribunales que sirven, especialmente, a los intereses de los grandes inversores, poniendo de manifiesto, de esta forma, la verdadera naturaleza del impulso que late el corazón del proceso de integración europeo.

\section{Bibliografía}

Alonso García, R. (2014). La cuestión prejudicial, piedra angular de la integración europea. European Inklings (EUi), 4, 9-27.

Ankersmit, L. (2016). The Compatibility of Investment Arbitration in EU Trade Agreements with the EU Judicial System. Journal for European Environmental \& Planning Law, 13 (1), 46-63.

Baratta, R. (2011). National Courts as «Guardians» and «Ordinary Courts» of EU Law: Opinion 1/09 of the ECJ. Legal Issues of Economic Integration, 38 (4), 297-320.

Basedow, J. (2015). EU Law in International Arbitration: Referrals to the European Court of Justice. Journal of International Arbitration, 32 (4), 367-386.

Blackaby, N. (2004). Public Interest and Investment Treaty Arbitration. Transnational Dispute Management, 1 (1).

Broches, A. (1995). The Experience of the International Centre for Settlement of Investment Disputes. En Selected Essays. World Bank, ICSID, and Other Subjects of Public and Private International Law, Boston: Martinus Nijhoff.

Brower, C. N. (2015). Are Fear, Disinformation, Politics and the European Commission becoming the Four Horsemen of the Apocalypse for International Investment Dispute Arbitration? Arbitraje. Revista de Arbitraje Comercial y de Inversiones, 8 (3), 653-686.

Burgstaller, M. (2012) Investor-State Arbitration in EU International Investment Agreements with Third States. Legal Issues of Economic Integration, 39, 207-221.

Cienfuegos Mateo, M. (2012). ¿Pueden las jurisdicciones internacionales plantear una cuestión prejudicial al Tribunal de Justicia? De nuevo sobre la noción co- 
munitaria de jurisdicción de un Estado miembro. Revista Española de Derecho Europeo, 41, 151-192.

- (2014). Noción de órgano jurisdiccional a los efectos de plantear una cuestión prejudicial. European Inklings (EUi), 4, 28-43.

Dias Simões, F. (2017). A Guardian and a Friend? The European Commission's Participation in Investment Arbitration. Michigan State International Law Review, 25, 233-303.

Díez-Hochleitner, J. (2015). El incierto futuro del arbitraje de inversiones (A propósito de las negociaciones del TTIP). La Ley Mercantil, 19, 1-7.

- (2017). La nueva política comercial de la Unión Europea desborda el marco de sus competencias. Comentarios preliminares al Dictamen 2/15 del TJUE. Revista de Derecho Comunitario Europeo, 57, 403-429.

Dimopoulos, A. (2011). The validity and applicability of international investment agreements between EU Member States under EU and international law. Common Market Law Review, 48 (1), 63-93.

- (2014). The involvement of the EU in investor-state dispute settlement: A question of responsibilities. Common Market Law Review, 51 (6), 1671-1720.

Dutheil De La Rochère, J. (2011). Quel rôle pour la Cour de Justice? En Le droit européen et l'arbitrage d'investissement (pp. 37-45). Paris: Éditions Panthéon-Assas.

Echaide, J. (2017). Inversiones y solución de controversias: el proyecto dentro de la Unasur y propuestas alternativas. Anuario Mexicano de Derecho Internacional, $17,369-403$.

Eeckhout, P. (2015). Opinion 2/13 on EU Accession to the ECHR and Judicial Dialogue: Autonomy or Autarky. Fordham International Law Journal, 38 (4), 955-992.

Fach Gómez K. (2016). The US-EU Transatlantic Trade and Investment Partnership: Should it leave a door open for non-legal arbitrators? Conflict Resolution Quarterly, 34 (2), 189-224.

— y Titi C. (2016). El Centro de Solución de Controversias en Materia de Inversiones de UNASUR: Comentarios Sobre el Borrador de Acuerdo Constitutivo. Investment Treaty News, 7 (3), 3-6.

— (2017). Unión Europea e inversiones internacionales: el futuro de los mecanismos de resolución de controversias inversor-Estado. Revista Española de Derecho Internacional, 69 (1), 295-302.

Fernández Masiá, E. (2004). Arbitraje en inversiones extranjeras: el procedimiento arbitral en el CIADI, Valencia: Tirant lo Blanch.

(2015). Hacia la creación de un Tribunal Internacional de Inversiones. Diario la Ley, 8650.

- (2017). Los mecanismos de solución de diferencias inversor-Estado en una encrucijada: del arbitraje a la creación de un Tribunal Multilateral, ¿pasando por un sistema de Tribunales internacionales de Inversiones? En K. Fach Gómez (ed.). La politica de la Unión Europea en materia de derecho de las inversiones internacionales (pp. 155-173). España: Bosch. 
Fernández Rozas, J. C. (2014). Conjeturas en torno a la nueva política global europea en materia de inversión internacional tras el Reglamento núm. 912/2014. La Ley Unión Europea, 18, 5-27.

— (2015). La confusa actuación de la Comisión Europea en el cambio del arquetipo regulador de la protección de inversiones transnacionales. La Lay Unión Europea, 28.

Franck, S. D. (2005). The Legitimacy Crisis in Investment Treaty Arbitration: Privatizing Public International Law through Inconsistent Decisions. Fordham Law Review, 73, 1521-1625.

García Antón, R. (2015). 'Ceci n'est pas une Pipe': The Notion of Tax Court under Article 267 of the TFEU. European Taxation, 55 (11), 515-522.

Gáspár-Szilágyi, S. (2016). A Standing Investment Court under TTIP from the Perspective of the Court of Justice of the European Union. The Journal of World Investment and Trade, 17 (5), 701-742.

González Alonso, L. N. (2012). ¿Fundamentalismo constitucional en Luxemburgo? El Tribunal de Justicia y los límites de la autonomía del sistema jurídico de la Unión Europea a la luz del Dictamen 1/09. Revista Española de Derecho Europeo, 43, 251-274.

González Vega, J. A. (2015). La «teoría del big bang» o la creciente distancia entre Luxemburgo y Estrasburgo. La Ley Unión Europea, 25, 1-43.

Govaere, I. (2010). Beware of the Trojan Horse: Dispute Settlement in (Mixed) Agreements and the Autonomy of the EU Legal Order. En Mixed agreements revisited: the EU and Its Member States in the World (pp. 187-207), Oxford: Hart.

Halberstam, D. (2015). «It's the Autonomy, Stupid!». A Modest Defense of Opinion 2/13 on EU Accession to the ECHR and the Way Forward. German Law Journal, 16 (1), 105-146.

Herrmann, C. (2014). The Role of the Court of Justice of the European Union in the Emerging EU Investment Policy. The Journal of World Investment and Trade, 15 (3-4), 570-584.

Hindelang, S. (2012). Circumventing Primacy of EU Law and the CJEU's Judicial Monopoly by Resorting to Dispute Resolution Mechanisms Provided for in Inter-se Treaties? The Case of Intra-EU Investment Arbitration. Legal Issues of Economic Integration, 39, 179-206.

(2013). The Autonomy of the European Legal Order. EU Constitutional Limits to Investor-State Arbitration on the Basis of Future EU Investment-Related Agreements. En European Yearbook of International Economic Law, special issue: Common Commercial Policy after Lisbon (pp. 187-198). Springer.

Hinojosa Martínez, L. M. (2015). El alcance de la competencia exterior europea en materia de inversiones. Revista de Derecho Comunitario Europeo, 52, 871-907.

Howse, R. (2017). International Investment Law and Arbitration. A conceptual Framework. IILJ Working Paper, 1. Disponible en: https://goo.gl/RYwAoJ.

Iruretagoiena Agirrezabalaga, I. (2015). Responsabilidad financiera resultante de los arbitrajes de inversión constituidos sobre la base de los futuros Acuerdos de 
inversión de la Unión Europea. Revista Española de Derecho Internacional, 67 (1), 335-338.

(2017a). Por fin un poco de luz en el farragoso debate competencial en el marco de los nuevos tratados de comercio e inversión de la Unión Europea (Dictamen 2/15 del Tribunal de Justicia de la Unión Europea). La Ley Unión Europea, 50, 1-19.

- (2017b). El capítulo sobre inversiones del Acuerdo Económico y Comercial Global de la Unión Europea y Canadá (CETA): análisis crítico de una iniciativa inacabada. Arbitraje. Revista de Arbitraje Comercial y de Inversiones, 10 (1), 41107.

Kleinheisterkamp, J. (2014). Financial Responsibility in European International Investment Policy. International and Comparative Law Quarterly, 63, 449-476.

Kokott, J. y Sobotta C. (2016). Investment Arbitration and EU Law. Cambridge Yearbook of European Legal Studies, 18, 3-19.

Lavranos, N. (2010). The ECJ's relationship with other international courts and tribunals. En K. Hagel-Sorensen, U. Haltern, H. Koch y J. Weiler (eds.). Europe-The New Legal Realism, Essays in Honour of Hjalte Rasmussen (pp. 393411). Copenhaguen: Djof Publishing.

- (2013). Designing an International Investor-to-State Arbitration System After Opinion 1/09. En European Yearbook of International Economic Law, special issue: Common Commercial Policy after Lisbon (pp. 199-219). Springer.

Lenk, H. (2017). Investment arbitration under EU investment agreements: is there a role for an autonomous EU legal order? European Business Law Review, 28 (2), $135-162$.

Lock, T. (2015). The European Court of Justice and International Courts. Oxford: Oxford University Press.

López Rodríguez, A. M. (2017). El Sistema de Tribunales de Inversión. Posibles incompatibilidades con el Derecho europeo. Cuadernos Europeos de Deusto, 57, 29-68.

Martín y Pérez de Nanclares, J. (2011). Unidad y pluralismo en la jurisprudencia del Tribunal de Justicia de la Unión Europea. Hacia un refuerzo de la autonomía del Derecho de la Unión frente al Derecho Internacional. En Unidady pluralismo en el Derecho Internacional público y en la Comunidad Internacional (Coloquio en Homenaje a Oriol Casanovas, Barcelona, 21-22 de mayo de 2009) (pp. 254-286). España: Tecnos.

- (2015). El TJUE pierde el rumbo en el dictamen 2/13: ¿merece todavía la pena la adhesión de la UE al CEDH? Revista de Derecho Comunitario Europeo, 52, 825-869.

Olík M. y Fyrbach D. (2011). The Competence of Investment Arbitration Tribunals to Seek Preliminary Rulings from European Courts. Czech Yearbook of International Law, 191-205.

Parra, A. R. (2014). The Convention and Centre for Settlement of Investment Disputes. Recueil des cours, 374, 313-410. 
Paschalidis, P. (2016). Case C-567/14 Genentech: EU Law Confronted with International Arbitration. European International Arbitration Review, 5 (1), 59-66.

Paschalidis, P. (2017). Arbitral tribunals and preliminary references to the EU Court of Justice. Arbitration International, 33 (4), 663-685.

Pascual Vives, F. (2015). La responsabilidad financiera y la participación en el arbitraje de inversiones de la Unión Europea y sus Estados miembros a la luz del Reglamento (UE) núm. 912/2014. Revista Española de Derecho Internacional, 67 (1), 294-298.

— (2017a). ¿Hay alternativas al arbitraje de inversión?: Redefiniendo la solución de las controversias relativas a inversiones extranjeras. En K. Fach Gómez (ed.). La politica de la Unión Europea en materia de derecho de las inversiones internacionales (pp. 175-200). España: Bosch.

(2017b). La Unión Europea y el arbitraje de inversión en el CETA y el TTIP. Revista Española de Derecho Internacional, 69 (1), 287-294.

Penadés Fons, M. (2016). El asunto Genentech y el alcance de la second look doctrine en la Unión Europea. Arbitraje. Revista de Arbitraje Comercial y de Inversiones, 9 (3), 817-833.

Pereira Coutinho, F. (2015). Tax Arbitration Courts and Preliminary References. En N. Villa-Lobos y T. Carvalhais Pereira (coord.). The Portuguese Tax Arbitration Regime (pp. 235-260). Coimbra: Almedina.

Reinisch, A. (2013). The EU on the Investment Path - Quo Vadis Europe? The Future of EU BIT s and other Investment Agreements. Santa Clara Journal of International Law, 12, 111-157.

- (2015). The European Union and Investor-State Dispute Settlement: From Investor-State Arbitration to a Permanent Investment Court. Disponible en https:// goo.gl/54qvxJ.

Rodriguez Medal, J. (2015). Concept of a Court or Tribunal under the Reference for a Preliminary Ruling: Who can Refer Questions to the Court of Justice of the EU? European Journal of Legal Studies, 8 (1), 104-146.

Rovetta, D. (2013). Investment Arbitration in the EU After Lisbon: Selected Procedural and Jurisdictional Issues. En European Yearbook of International Economic Law, special issue: Common Commercial Policy after Lisbon (pp. 221-233), Springer.

Sánchez Rodríguez, A.J. (2013). Acceso de los órganos arbitrales nacionales al procedimiento prejudicial del TJUE. Revista General de Derecho Europeo, 35, 1-38.

Schill, S. W. (2013). Luxembourg Limits: Conditions for Investor-State Dispute Settlement under Future EU Investment Agreements. En M. Bungenberg, A. Reinisch y C. Tietje (eds.) EU and Investment Agreements. Open Questions and Remaining Challenges (pp. 37-54). Baden-Baden: Nomos.

- (2015). Editorial: Opinion 2/13. The End for Dispute Settlement in EU Trade and Investment Agreements? The Journal of World Investment and Trade, 16, 379-388.

Schmalenbach, K. (2008). Struggle for Exclusiveness: The ECJ and Competing International Tribunals, en International Law Between Universalism and Frag- 
mentation: Festschrift in Honour of Gerhard Hafner (pp. 145-168). Netherlands: Brill.

Soca Torres, I. (2015). El concepto de órgano jurisdiccional en el planteamiento de la cuestión prejudicial europea [tesis doctoral]. Universitat Ramón Llull.

Strik, P. (2010). From Washington with Love. Investor-State Arbitration and the Jurisdictional Monopoly of the Court of Justice of the European Union. Cambridge Yearbook of European Legal Studies, 12, 425-453.

UNCTAD. (2017). Special Update on Investor-State Dispute Settlement: Facts and Figures, IIA Issues Note. Disponible en: https://goo.gl/2ykTxC.

Van Rossem, J. W. (2013). The Autonomy of EU Law: More is Less? En R. A. Wessel y S. Blockmans (eds.). Between Autonomy and Dependence. The EU Legal Order Under the Influence of International Organisations (pp. 13-46). The Hague: Springer.

Vatsov, M. (2014). The Mackerel War: testing the limits of the exclusive jurisdiction of the Court of Justice under Article 344 TFEU. European Law Review, 39, 864-878.

Von Papp, K. (2013). Clash of 'Autonomous Legal Orders': Can EU Member State Courts Bridge the Jurisdictional Divide between Investment Tribunals and the ECJ? A Plea for Direct Referral from Investment Tribunals to the ECJ. Common Market Law Review, 50, 1039.

Wehland, H. (2009). Intra-EU Investment Agreements and Arbitration: Is European Community Law an Obstacle? International Comparative Law Quaterly, 58, 297-320.

Zelazna, E. (2017). Assessment of the Jurisdictional Conflict between the CJEU and Investor-State Tribunals from the Perspective of Neofunctionalism. En K. Fach Gómez (ed.). La politica de la Unión Europea en materia de derecho de las inversiones internacionales (pp. 85-109). España: Bosch. 